\title{
LOS UNOS Y LOS OTROS: CONTRAPOSICIÓN Y REFLEXIONES SOBRE UNIVERSOS EXPRESIVOS DEL NOA PREHISPÁNICO
}

\author{
THE ONE AND THE OTHER: CONTRAPOSITION AND \\ REFLECTIONS ON EXPRESSIVE UNIVERSES OF PREHISPANIC NOA
}

INÉS GORDILLOA \& MARA BASIILE

En este trabajo discutimos las relaciones entre universos expresivos de dos momentos y lugares específicos: Período Medio (ca. 600-1200 AD) en el Valle de Ambato y Período de Desarrollos Regionales (ca. 1200-1400 AD) en la Región de Fiambalá. Ambos discursos visuales, desplegados en soportes rupestres y cerámicos, son analizados con criterios comunes y confrontados bajo el enfoque de la "analogía débil", que admite la existencia de una diferencia radical entre los fenómenos. Este doble ejercicio de contraposición constituye una suerte de estrategia metodológica para caracterizarlos más profundamente y para identificar e interpretar sus semejanzas/diferencias.

Palabras clave: Cerámica, Arte rupestre, Repertorio figurativo, Período Medio, Período de Desarrollos Regionales, Catamarca.

In this paper we discuss the relationships between expressive universes of two specific times and places: the Middle Period (ca. 600-1200 AD) in the Ambato Valley and the Regional Developments Period (ca. 1200-1400 AD) in Fiambalá Region. Both visual discourses, as expressed in two media, rock and ceramic, are analyzed using common criteria and compared from the lens of "weak analogy," which admits the existence of a radical difference among phenomena. This double-contrast exercise is a kind of methodological strategy to enable more in-depth characterization and to identify and interpret the similarities and differences of the two universes.

Keywords: Ceramics, Rock Art, Figurative Repertory, Middle Period, Regional Developments Period, Catamarca.

\section{LA PROPUESTA}

La presente propuesta consiste en profundizar la caracterización de dos universos expresivos diferentes del NOA prehispánico reformulando el análisis a partir de su confrontación. Tales universos, distanciados en tiempo y espacio, corresponden al Período Medio (ca. 600-1200 AD) en el Valle de Ambato y al Período de Desarrollos Regionales o Intermedio Tardío (ca. 12001400 AD) en la Región de Fiambalá, ambos ubicados en la actual Provincia de Catamarca (fig. 1).

Con ese propósito, planteamos una línea de trabajo comparativa que permita identificar las propiedades y relaciones de y entre conjuntos bajo los términos de lo que Criado Boado (1999) denomina "analogía débil" y define como "una relación de semejanza entre dos o más fenómenos que, en vez de ser utilizada para establecer una correspondencia positiva o continuidad entre ellos, sirve para, habida cuenta de su irreductibilidad mutua, percibir aspectos de uno de ellos a partir de su contraposición con los otros" (Criado Boado 1999: 12).

Si bien, no estamos seguras del tipo de relación existente entre estos dos "fenómenos", la idea es no suponer en principio ningún tipo de relación de iden-

A Inés Gordillo, Instituto de Arqueología, Facultad de Filosofía y Letras, Universidad de Buenos Aires, 25 de mayo 2017, 3er piso, CABA. E-mail: ibesalu@gmail.com

B Mara Basile, Instituto de las Culturas (IDECU), Universidad de Buenos Aires, COnICET, Facultad de Filosofía y Letras, Museo Etnográfico J. B. Ambrosetti, Moreno 350 (1091), CABA E-mail: basilemara@gmail.com.ar 


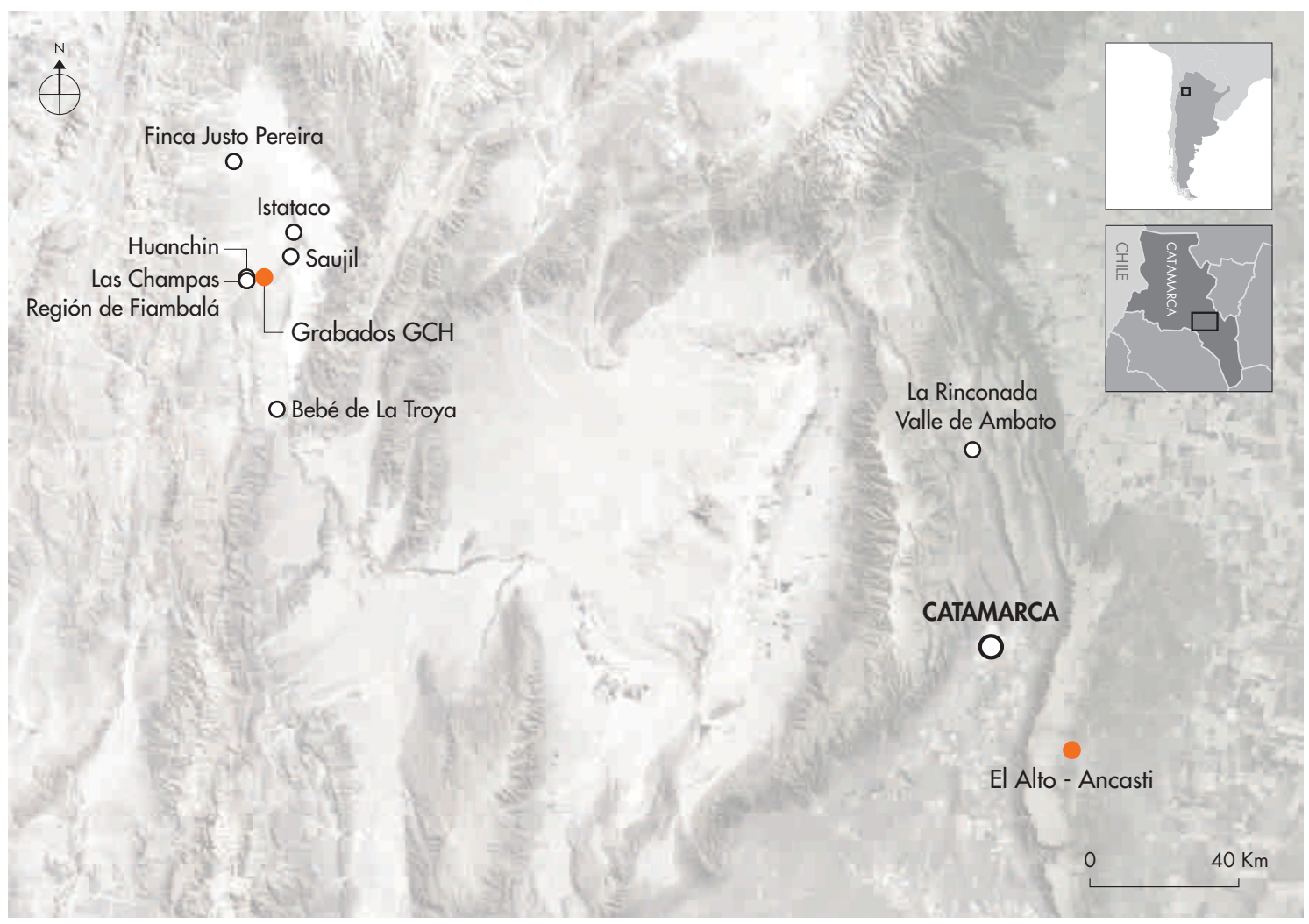

Figura 1. Ubicación de los sitios y localidades de procedencia de los materiales cerámicos y rupestres analizados. Figure 1. Location of the sites and localities of provenance of the ceramic and rock materials analyzed.

tidad o genética e implementar esta perspectiva de la analogía débil basada en la existencia de una diferencia radical entre los fenómenos. $\mathrm{Al}$ respecto, creemos que este doble ejercicio de contraposición constituye una suerte de estrategia metodológica para caracterizar más acabadamente a cada uno de ellos, así como para identificar, evaluar e interpretar la existencia de semejanzas y diferencias de repertorios o formas de configuración de las imágenes entre distintos lugares y tiempos. En definitiva, intentamos aquí caracterizar ambos discursos visuales interpretando el uno con el otro.

\section{DIMENSIONES DE ANÁLISIS}

Dado que el objetivo es contraponer los universos expresivos de contextos históricos particulares del NOA prehispánico, nuestra propuesta metodológica se orientó a explorar distintas dimensiones de análisis que permitan definir criterios comunes y ejes de comparación entre las dos muestras seleccionadas. En ese marco fue necesario también acordar nociones y categorías usuales en el análisis de las representaciones visuales pero que no siempre se hacen explícitas.

En esta primera instancia decidimos hacer foco en la figuración, es decir, en aquellas representaciones que responden a una tentativa de aprehensión de las formas externas y permiten reconocer, parcial o totalmente, elementos del mundo objetivo, definiendo relaciones de semejanza con el objeto referente. Tales imágenes pueden ser de carácter realista, cuando recrean modelos de existencia física, o bien de carácter fantástico o quimérico, cuando se trata de creaciones imaginarias que combinan elementos reales (sensu Gordillo 2004).

Esta decisión metodológica de abordar las expresiones figurativas responde a la necesidad de establecer un recorte que permita hacer comparables las muestras, tomando en consideración el predominio definitivo de la figuración dentro del repertorio expresivo del Período Medio en Ambato, aún cuando sabemos que 
esta situación tiende a invertirse en el repertorio del Período de Desarrollos Regionales aquí considerados.

La mayoría de las expresiones aquí analizadas corresponden, además, a sistemas de representación plana o bidimensional, más allá de su frecuente despliegue sobre soportes curvos. Este tipo de representaciones, figurativas y bidimensionales, exige eliminar una de las dimensiones del mundo real (reducción bidimensional) abstrayendo de él los atributos diagnósticos que lo hagan reconocible y replanteándolos mediante un lenguaje plástico con recursos o procedimientos formales específicos (Gordillo 2009).

Paralelamente, es preciso aclarar que empleamos como unidad de análisis al "motivo", de acuerdo a nuestros trabajos anteriores que sirven de base a este (Basile \& Ratto 2011, Ratto \& Basile 2013, Basile 2013a y b). Intentamos así hacer coincidir nuestra unidad de análisis con la unidad gráfica/conceptual del discurso visual, cuya delimitación formal y semántica conlleva la noción de motivo (Gordillo 2014a). En alguna medida, este es independiente del soporte y la técnica de ejecución, más allá del condicionamiento que estos factores le imponen. Por eso, los criterios de clasificación aluden fundamentalmente a cuestiones de composición, morfología y analogía. Sobre esta base y, como antes señalamos, la existencia o no de un correlato formal reconocible con el mundo físico deriva en la división en motivos de carácter figurativo y no-figurativo. ${ }^{1}$

\section{¿Qué se representa?}

El repertorio temático de cualquier estilo o conjunto expresivo supone una elección entre las infinitas posibilidades que ofrece el mundo físico e imaginario para ser representadas. En este recorte se ponen en juego procesos de selección e interpretación condicionados social e ideológicamente, por lo que la misma temática se constituye como un aspecto cargado de significación a la hora de analizar el discurso visual de cualquier grupo humano. Podríamos preguntarnos por qué se elige representar tal o cual elemento y no otros, pero para ello es necesario conocer previamente qué es lo que se representa. En esta primera aproximación, centrada en los repertorios figurativos, intentamos reconocer los modelos o referentes de cada motivo o significante a partir de relaciones de semejanza formal.

Como vimos, los motivos figurativos representados pueden clasificarse en realistas y fantásticos según refieran a elementos de existencia física o imaginaria. Los primeros son íconos que representan en forma "completa" al modelo o bien aluden a él a través de sus partes componentes o asociadas, a manera de índices (Peirce 1894). Estos últimos, entre los que incluimos los dibujos de manchas, garras, picos, fauces o huellas, actúan por sustitución metonímica a partir de relaciones de causalidad, procedencia o sucesión que establecen con el objeto referente.

Si bien nuestra unidad de análisis son los motivos, no desconocemos que los mismos integran también composiciones de distinto tipo al ubicarse en el espacio y relacionarse con otros elementos. Cada composición puede entenderse también como unidad y totalidad no aleatoria que tiene propiedades y significados complementarios a la mera reunión de motivos particulares. Las relaciones y distribución de los motivos en ellas, y las asociaciones recurrentes que puedan establecerse en esos términos, introducen un plano de significación que va más allá de la configuración formal de cada componente. En ese sentido, intentamos aquí visualizar y señalar algunas relaciones entre los mismos, tanto en composiciones estáticas, como escénicas y secuenciales que aparecen en nuestros universos expresivos.

\section{¿Cómo se representa?}

Son varios los elementos que confluyen en la creación de una imagen y definen la forma de representar. En términos generales, consideramos puntualmente los siguientes aspectos:

- técnicas de ejecución (grabado/incisión, escisión, pintura, modelado, etc.).

- clases de contraste que permiten definir las formas (contrastes de matiz, de valor y de textura visual/ táctil) en su carácter positivo y/o negativo.

- planos de la composición: dos planos (figura-fondo, fijo o reversible) y múltiples planos (superposición, perspectiva, etc.).

- espacios compositivos: delimitados (bandas, paneles, etc.) y abiertos (sin encuadre).

Si bien todos estos aspectos son significativos a la hora interpretar nuestros universos expresivos, nos interesa abordar in extenso las formas de representación de los motivos. Estos se constituyen, según lo definido previamente, como unidad formal/semántica del diseño 
y por ello ofrecen amplias posibilidades de análisis y sistematización para el reconocimiento de las lógicas de representación que organizan al discurso visual.

Como vimos, nuestra primera clasificación, que alude a lo representado, ordena los motivos en reales y fantásticos. Paralelamente, al considerar la manera en que se representan, los motivos pueden definirse por su forma simple o compuesta (Kusch 1991). Los primeros hacen referencia a una sola especie o categoría de modelos objetivos, sin combinaciones o agregados de segmentos corporales. Por el contrario, los motivos compuestos reúnen en una sola imagen atributos inter o intra-especie. Esta categoría de motivos corresponde generalmente a figuras de carácter fantástico o imaginario, aunque en ocasiones pueden recrear o aludir a modelos reales, constituyéndose como representaciones visuales de representaciones fácticas. ${ }^{2}$ Entonces, integrando las clasificaciones aquí planteadas, se definen básicamente tres grupos de motivos:

1) realistas y simples: representación de un referente fáctico.

2) realistas compuestas: representación (o meta-representación) de un referente fáctico combinado.

3) fantásticos y compuestos: representación combinada de referentes fácticos en uno ficticio.

De esta manera, cualquier motivo realista (simple o compuesto) puede adquirir carácter fantástico al integrar elementos derivados del mismo u otro tipo de motivos. Cabe señalar que, lo que se combina no son los modelos, sino la forma en que los mismos se representan, por lo cual resulta sustancial abordar el patrón de representación que rige la clase de motivos simples.

Con esa idea, para definir ese patrón de representación y acceder a aspectos más estructurales y conceptuales del diseño, consideramos particularmente los "atributos de composición". Los mismos están referidos a la vista (frontal, perfil, aérea, etc.), la orientación (vertical, horizontal, oblicua, etc.) y la actitud o postura (erguida, sentada, supina, etc.), junto con su distribución dentro del campo decorativo (central, lateral, sucesiva, etc.) y las posibilidades combinatorias recurrentes para formar motivos compuestos (humano-felino, humano-ave, felino-ofidio, felino-felino, etc.) (Gordillo 2009). En general, los componentes que se aíslan y combinan de cada motivo tienden a mantener las cualidades compositivas que lo definen en su forma simple, aspecto que ya fue señalado por Kusch (1991) en su análisis general de la iconografía Aguada.

En este marco, cobran especial importancia los procedimientos compositivos empleados en la construcción de las figuras compuestas o combinadas. Al respecto, siguiendo la analítica propuesta por una de nosotras (Gordillo 2009 y 2014b), los mismos pueden ordenarse en función de los siguientes modos de combinar:

a. Por combinación morfológica de distintos referentes.

b. Por combinación actitudinal o conceptual, donde el sentido dual o múltiple de la figura se define por la contraposición de atributos formales/conceptuales, tales como la actitud postural, el gesto, la orientación, la acción, etc.

c. Por ambigüedad óptica o formal, cuando la figura propone interpretaciones excluyentes durante el acto perceptivo y permite identificar distintos referentes. Las mismas pueden definirse como:

- Espejadas (por simetría bilateral): las dos mitades opuestas -referidas a un determinado motivo simple o compuesto- generan, al enfrentarse o adosarse, otra imagen de carácter diferente (Split representation, sensu Levi Strauss 1967).

- Anatrópicas (por rotación): el carácter ambivalente se manifiesta según la posición en que se observan (González 1974). Girando el diseño, se define otra imagen que reemplaza a la anterior, aun cuando está conformada por los mismos trazos o volúmenes.

- Alternas: la ambigüedad se establece por mecanismos de reversibilidad figura-fondo, contornos comunes, cerramientos incompletos, etc.

\section{¿Dónde se representa?}

Finalmente, resulta importante al análisis determinar dónde se despliegan estas imágenes. Para ello, hemos considerado fundamentalmente el tipo de soportes y de contextos. Los universos expresivos aquí confrontados corresponden a recipientes cerámicos y a superficies rocosas inmuebles. Cada clase de soporte, según sus características (movilidad, textura, tamaño, conformación, etc.), ofrece potenciales diferentes de ejecución, apreciación y uso del discurso visual. Al respecto, no es lo mismo relacionarse con objetos/imágenes fijos o móviles, o bien manipular un símbolo que verse envuelto por él. Las diferencias no solo aluden a los aspectos técnicos y 
a las posibilidades o no de movimiento y manipulación. Cada tipo de arte/soporte plantea relaciones espaciales particulares entre los sujetos creadores o consumidores y la obra, en función de la ubicación, distribución, tamaño, forma, colores y textura de la imagen y su soporte. Estas características van a definir, sin duda, variaciones sensibles en cuanto al gesto corporal, campo visual, a las formas, alcances e impacto perceptivo, a las sensaciones provocadas, a las prácticas promovidas, etc.

Desde el punto de vista compositivo, el objeto impone los límites del diseño, aunque este pueda definirse con distintos grados de amplitud dentro o entre los mismos, de manera tal que podemos identificar los espacios compositivos e indagar acerca de la articulación entre sus componentes visuales. En el arte rupestre, no siempre es posible definir los límites del diseño y la relación entre las representaciones, ya sea por la continuidad, las posibilidades de reutilización a lo largo del tiempo, las características del soporte rocoso o el estado de conservación (Gordillo 2001).

En relación al contexto las posibilidades son varias. En el arte rupestre, estará definido por las características y distribución de los soportes rocosos, así como por sus asociaciones con otros materiales y tipos de sitios que evidencian las variadas prácticas a las que estaba o no vinculada su producción y uso/consumo. Por otro lado, la procedencia de las muestras cerámicas permite definir en principio, y según sea el caso, contextos de vivienda, tránsito o funerarios, mostrando en algunos casos variedad de usos inmediatos y prácticas asociadas.

\section{LAS MUESTRAS ANALIZADAS}

\section{Período Medio en el Valle de Ambato (600-1200 AD)}

En relación con el universo Aguada retomamos una muestra previamente trabajada (Gordillo 1998 y 2009) con resultados cuya revisión, ajuste y reformulación permitió adoptar la perspectiva comparativa que proponemos en el presente análisis. La muestra está conformada mayormente por materiales cerámicos correspondientes a los estilos cerámicos Ambato Negro Grabado y Ambato Pintado que fueron recuperados en las excavaciones sistemáticas de habitaciones, patios y plataformas del sitio conocido como Iglesia de los Indios (La Rinconada, Dpto. Ambato, Catamarca, Argentina) (Gordillo 2004).
Se suman también las vasijas decoradas procedentes de otros sitios de ocupación -como Los Martínez- excavados en el valle de Ambato, cuya descripción y análisis se basó en las ilustraciones y datos publicados por Ávila y Herrero (1991), Assandri (1991), Juez (1991), Bedano, Juez y Roca (1993). La muestra se vio ampliada con el examen de piezas enteras halladas en la misma zona y correspondientes a la colección Rosso (Córdoba), al Museo Arqueológico "Adán Quiroga" (Catamarca), a la colección Marengo-Petek (Catamarca) y al Museo Etnográfico de Buenos Aires. A diferencia de las otras, para la mayoría de las piezas de colecciones solo contamos con los datos de procedencia a escala regional, pero no de su contexto de hallazgo específico. Cabe señalar que no hemos incorporado a la muestra los datos del arte rupestre Aguada, como sí lo hicimos con parte de la muestra tardía. Tales manifestaciones, especialmente las del sector centro-sur de la sierra de Ancasti que vienen siendo estudiadas por otros autores (Nazar et al. 2014) enriquecerán esta línea de análisis en los trabajos futuros que hemos previsto como continuidad del presente.

En términos numéricos, las piezas son 180 (117 de La Rinconada y otros sitios de Ambato, y 63 de colecciones) y los motivos analizados suman 219 , de los cuales 168 son figurativos (correspondientes a 143 de las180 piezas) (tabla 1$)$.

\section{Período de Desarrollos Regionales en la Región de Fiambalá (ca. 1200-1400 AD)}

Para abordar el universo expresivo del período de Desarrollos Regionales en la región de Fiambalá analizamos una muestra de 53 piezas cerámicas estilo Belén, cerradas (33:53) y abiertas (20:53), que presentan en sus superficies motivos figurativos. En esas piezas hay 510 motivos, de los cuales 375 son no figurativos (trazos lineales, escalonados y círculos) y 110 son figuras zoomorfas, 18 son huellas felínicas y 6 son figuras humanas (tabla 1).

Estas piezas son resultado de intervenciones arqueológicas en sitios de la región (finca Justo Pereira y Bebé de La Troya) y del relevamiento de colecciones realizadas en el marco de las investigaciones conducidas allí por el Proyecto Arqueológico Chaschuil-Abaucán (PAChA) a lo largo del tiempo. Las colecciones se encuentran depositadas en instituciones museográficas (Museo del Hombre -Fiambalá-, Museo Robaudi -Tinogasta-, Museo Provincial Inca huasi -La Rioja-, Jesuítico de Jesús María -Córdoba-), o en manos de particulares 
Tabla 1. Presentación de las muestras analizadas para el Período Medio y el de Desarrollos Regionales en Ambato y Fiambalá, respectivamente. Table 1. Data on samples analyzed for the Middle and the Regional Developments periods in Ambato and Fiambalá, respectively.

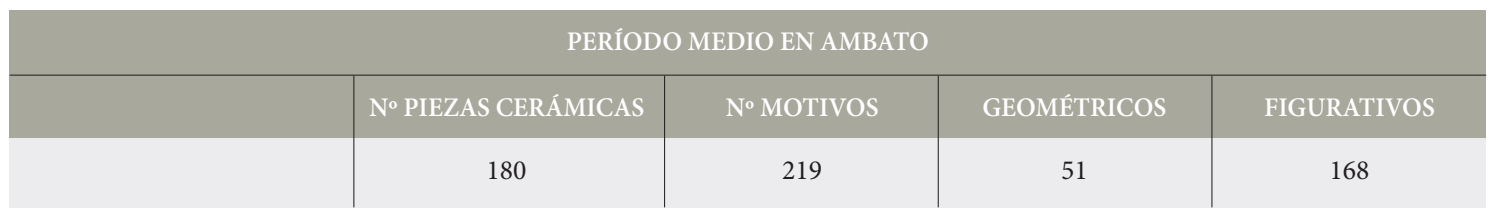

\begin{tabular}{|c|c|c|c|c}
\multicolumn{5}{|c|}{ PERIOODO DE DESARROLLOS REGIONALES EN FIAMBALÁ } \\
\hline & No PIEZAS CERÁMICAS & No MOTIVOS & GEOMÉTRICOS & FIGURATIVOS \\
\hline No BLOQUES GRABADOS & 53 & 510 & 375 & 135 \\
\hline
\end{tabular}

(Colección Bayón -Fiambalá-, Colección Pereira-Saujil-) y provienen de intervenciones asistemáticas en los distintos ambientes, pueblos y parajes de la región de Fiambalá (Istataco, Huanchín, Las Champas, Saujil). Cada colección tiene sus particularidades y solo en algunos casos, especialmente en los que se puede apelar a la memoria de los pobladores que las conformaron, brindan la posibilidad de rearmar los contextos, generalmente funerarios, e incluso de datarlos (Basile \& Ratto 2016, Ratto et al. 2016).

Además, incluimos en el análisis las imágenes grabadas en los bloques de arenisca roja del sitio Guanchincito que se encuentra asociado a una amplia extensión de cuadros de cultivo entre los que se documentaron cámaras funerarias en cista y ha sido adscrito en forma relativa al mismo lapso (Ratto 1996, Ratto et al. 20002002, Basile \& Ratto 2014, entre otros). En este sitio se han relevado 22 bloques, 12 de los cuales presentan motivos figurativos en sus caras grabadas. En estos 12 bloques se han documentado 177 motivos, de los cuales 53 son figurativos (tabla 1).

\section{ANÁLISIS Y RESULTADOS}

\section{El caso Aguada}

En la muestra Aguada de Ambato existe un claro predominio de los motivos figurativos (168: 219/76,71\%) sobre los geométricos (51: 219/23,29\%). Estos últimos comprenden rombos, triángulos escalonados, círculos, cruces, etc. y sus combinaciones; ${ }^{3}$ con frecuencia se distribuyen por repetición dentro de campos delimitados planteando la reversibilidad figura-fondo como recurso estrategia compositiva. En otros casos integran diseños con representaciones de carácter figurativo.

Dentro de los motivos figurativos, los referentes representados son animales y humanos, los que se ven acompañados en algunos casos de armas y adornos. Las figuras realistas simples son: antropomorfos, felinos, ofidios y aves, con atributos configurativos y compositivos específicos (tabla 2). En este conjunto, el felino es dominante (45: 168/26,78\%) (fig. 2), seguida por la figura humana (29: 168/17,26\%) (fig. 3).

Asimismo, se identificó la representación de huellas (2) asociadas a felinos realistas en una vasija cerrada (ver fig. 2, abajo). Cabe señalar que las pisadas de felino aparecen también representadas el arte rupestre de la sierra Ancasti, como ha sido registrado en los sitios de La Candelaria y Casa Pintada (Gordillo 2015).

Las figuras compuestas, tanto realistas como fantásticas, constituyen casi la mitad de las representaciones figurativas (80: 168/47,61\%). La categoría de motivos compuestos realistas, alrededor de un $10 \%$, es siempre antropo-felínica (HF) y sugiere la representación de individuos disfrazados o transformados en jaguares (figs. 4 y 5). Los motivos compuestos de carácter fantástico o imaginario están ampliamente representados en la muestra figurativa (64: 168,38,31\%), especialmente a través de las figuras multicéfalas (en la tabla 2 corresponden a FF, FO y FZ), altamente normalizadas en términos técnicos y formales. Por lo demás, el repertorio de esta 

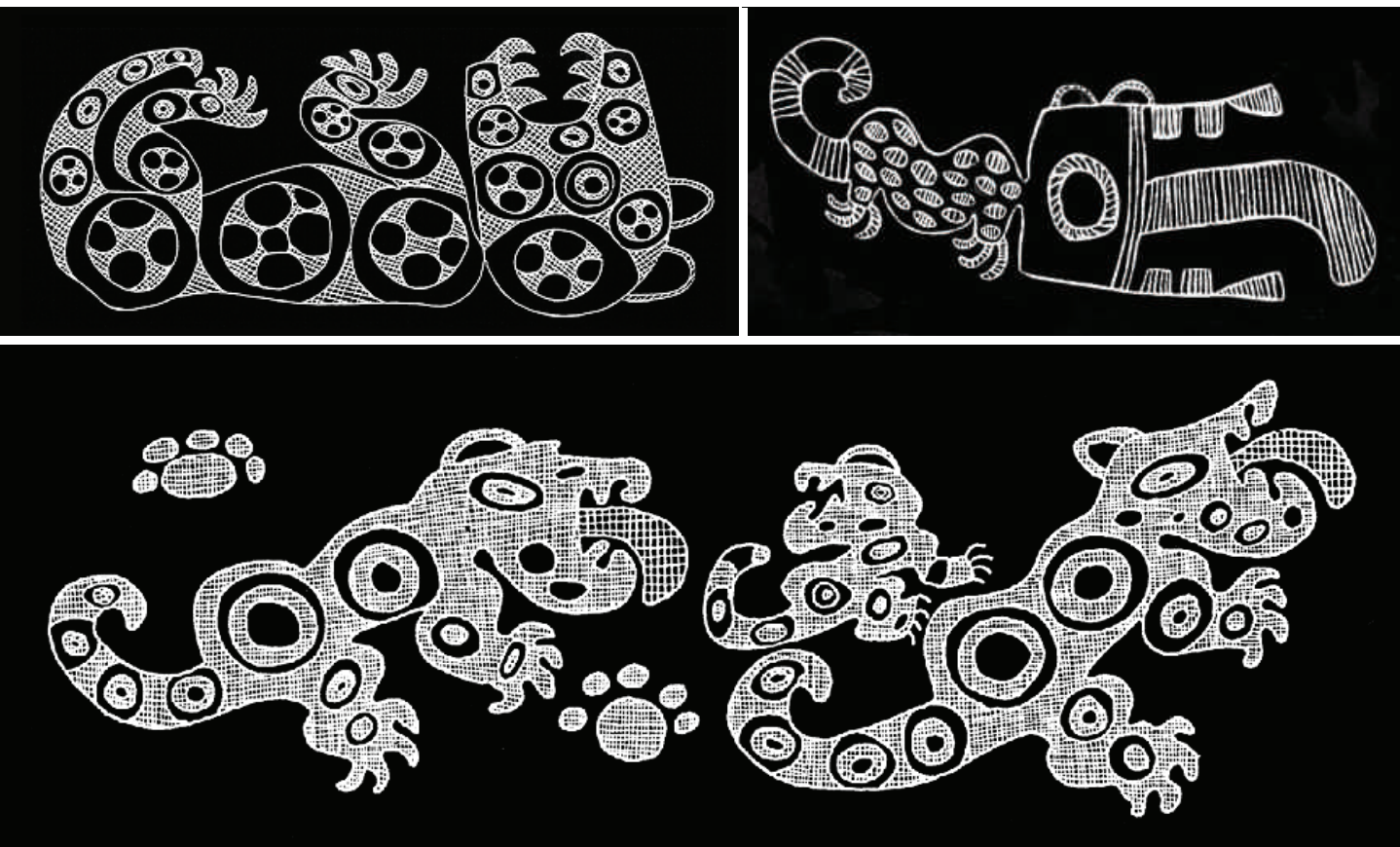

Figura 2. Representaciones del felino (jaguar) como motivo realista simple procedentes de La Rinconada (E1) y de la colección Petek (arriba). La escena de felinos y sus huellas corresponde a la colección Rosso (abajo). Largo de los diseños: $20 \mathrm{~cm}, 17 \mathrm{~cm}$ y $31,5 \mathrm{~cm}$, respectivamente. Figure 2. Representations of the feline (jaguar) as a simple lifelike motif in La Rinconada (E1) and the Petek collection (above). The scene of felines and their footprints is from the Rosso collection (bottom). Length of the designs: $20 \mathrm{~cm}, 17 \mathrm{~cm}$ and $31.5 \mathrm{~cm}$, respectively.
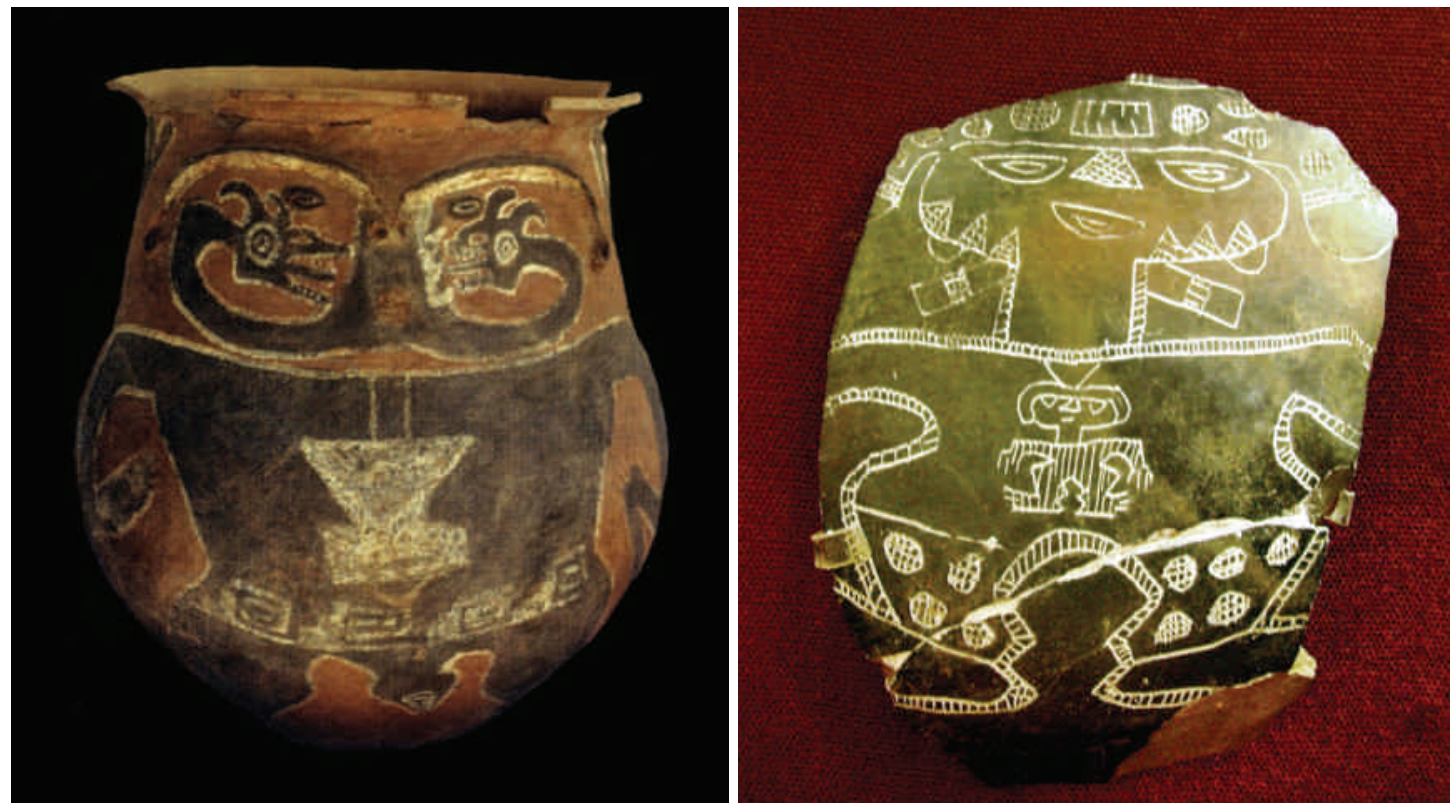

Figura 3. Figura humana pintada sobre una tinaja de la colección Rosso (tomada de González 1998: 182, fig. 116) y grabada en un fragmento de olla (Museo de Antropología de Córdoba). Altura de las piezas: $50 \mathrm{~cm} \mathrm{y} \mathrm{10,5} \mathrm{cm,} \mathrm{respectivamente.} \mathrm{Figure} \mathrm{3.} \mathrm{Human}$ figure painted on a vessel from the Rosso collection (taken from González 1998:182, fig. 116) and engraved on a fragment of pot (Museo de Antropología de Córdoba). Height of the pieces: $50 \mathrm{~cm}$ and $10.5 \mathrm{~cm}$, respectively. 
Tabla 2. Frecuencias de los motivos identificados en la muestra de Ambato, sus técnicas de ejecución y formas (abiertas y cerradas) asociadas. Table 2. Frequency of motifs, techniques used, and associated forms (open and closed) identified in the Ambato sample.

\begin{tabular}{|c|c|c|c|c|c|c|c|c|c|}
\hline \multirow{2}{*}{\multicolumn{2}{|c|}{ MOTIVOS }} & & \multicolumn{3}{|c|}{ TÉCNICAS } & \multirow[b]{2}{*}{$\begin{array}{l}\text { FIGURACIÓN } \\
\qquad(\%)\end{array}$} & \multirow[b]{2}{*}{$\begin{array}{c}\text { MUESTRA } \\
(\%)\end{array}$} & \multicolumn{2}{|c|}{ FORMAS } \\
\hline & & & GRABADO & PINTURA & TOTAL & & & A & $\mathrm{C}$ \\
\hline \multirow{6}{*}{$\frac{\ddot{s}}{\tilde{E}}$} & \multirow{7}{*}{ 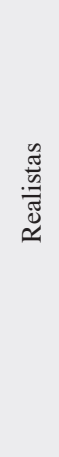 } & Felino (F) & 39 & 6 & 45 & 26,786 & & $\mathrm{X}$ & $\mathrm{X}$ \\
\hline & & Humano $(\mathrm{H})$ & 20 & 9 & 29 & 17,26 & & $\mathrm{X}$ & $\mathrm{X}$ \\
\hline & & Ofidio (O) & 4 & 2 & 6 & 3,57 & & $\mathrm{X}$ & $\mathrm{X}$ \\
\hline & & Ave (Or) & 3 & 1 & 4 & 2,38 & & $\mathrm{X}$ & $\mathrm{X}$ \\
\hline & & Saurio (S) & 2 & - & 2 & 1,19 & & $\mathrm{X}$ & $\mathrm{X}$ \\
\hline & & Huellas felino (hf) & 2 & - & 2 & 1,19 & & & $\mathrm{X}$ \\
\hline \multirow{7}{*}{ 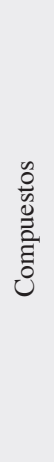 } & & Felino-humano (HF) & 16 & - & 16 & 9,52 & & $\mathrm{X}$ & $\mathrm{X}$ \\
\hline & \multirow{6}{*}{ 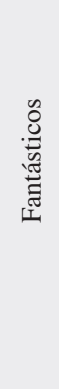 } & Felino-felino (FF) & 32 & - & 32 & 19,05 & & $\mathrm{X}$ & $\mathrm{X}$ \\
\hline & & Felino-ofidio (FO) & 7 & 5 & 12 & 7,14 & & $X$ & $\mathrm{X}$ \\
\hline & & Ofidio-ofidio (OO) & 2 & 1 & 3 & 1,79 & & $\mathrm{X}$ & $\mathrm{X}$ \\
\hline & & Felino-zoomorfos (FZ) & 11 & 2 & 13 & 7,74 & & $\mathrm{X}$ & \\
\hline & & Felino-ave (FOr) & 2 & - & 2 & 1,19 & & & $\mathrm{X}$ \\
\hline & & Felino-hombre-ave (FHOr) & 2 & - & 2 & 1,19 & & $\mathrm{X}$ & $\mathrm{X}$ \\
\hline \multicolumn{3}{|c|}{ Total figurativos } & 142 & 26 & 168 & 100 & 76,71 & $\mathrm{X}$ & $\mathrm{X}$ \\
\hline \multicolumn{3}{|c|}{ Total geométricos } & 41 & 10 & 51 & & 23,29 & $\mathrm{X}$ & $\mathrm{X}$ \\
\hline \multicolumn{3}{|c|}{ TOTAL } & 183 & 36 & 219 & & 100 & & \\
\hline
\end{tabular}
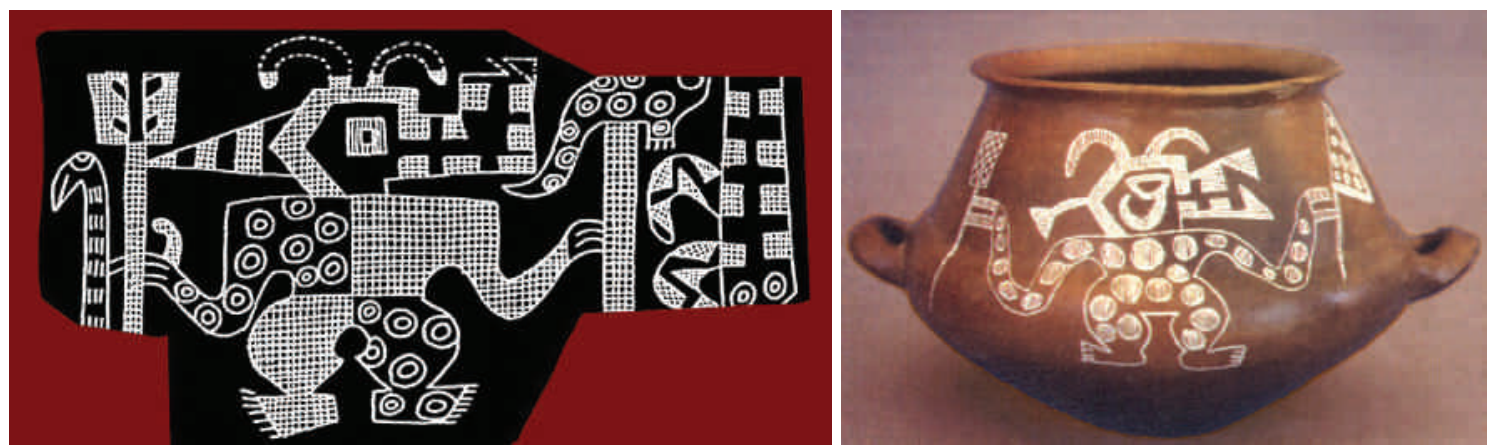

Figura 4. El "enmascarado" en un fragmento de La Rinconada (E7) y en una olla de la colección Rosso (tomada de González 1998, fig. 158, p. 211). Altura de los motivos: 10,2 cm y $8 \mathrm{~cm}$, respectivamente. Figure 4. The "masked one" on a sherd from La Rinconada (E7) and on a pot in the Rosso collection (taken from González 1998, fig 158, page 211). Height of the motifs: $10.2 \mathrm{~cm}$ and $8 \mathrm{~cm}$, respectively. 

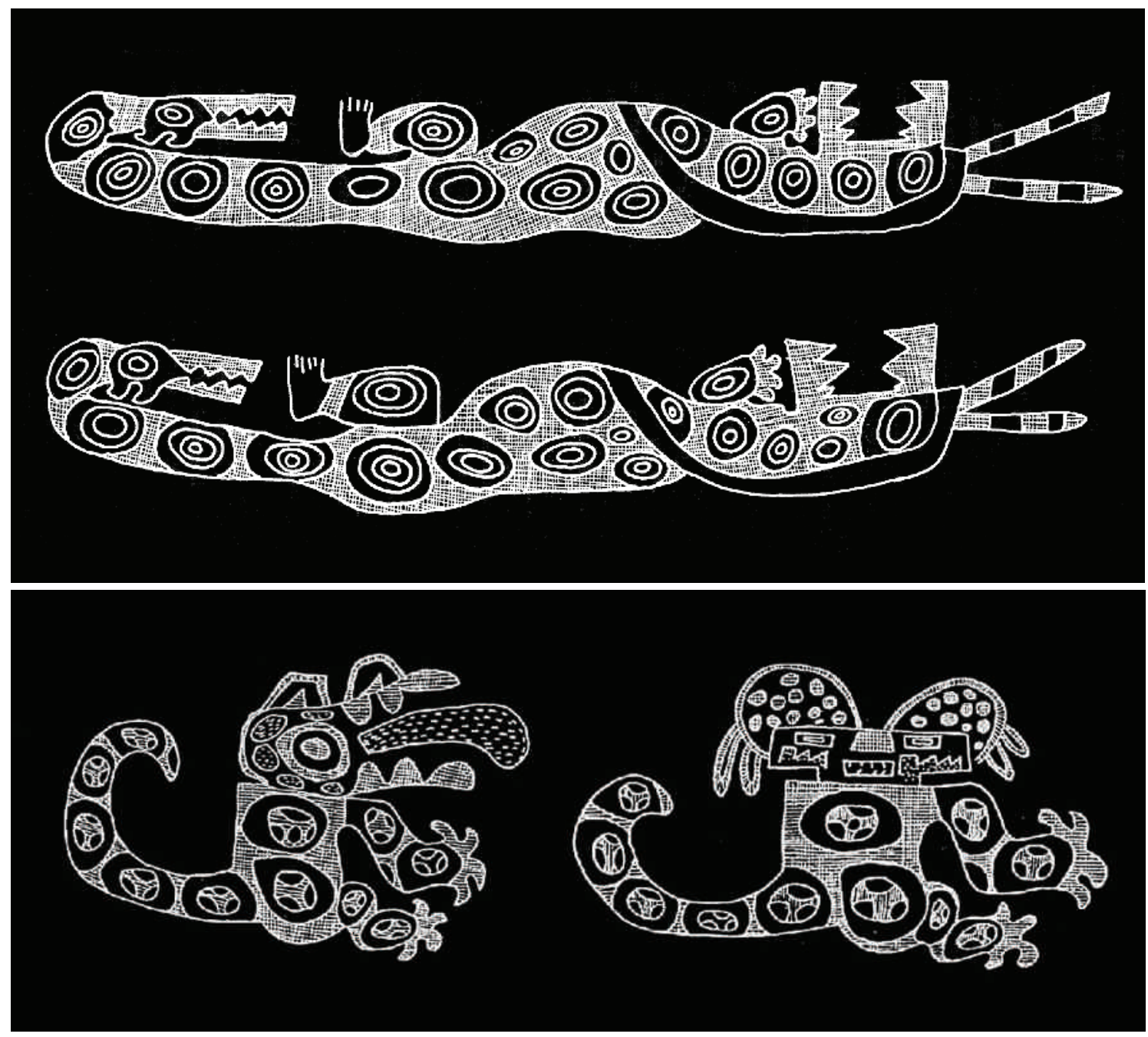

Figura 5. Motivos humano-felínicos en piezas de la colección Rosso. Los de arriba miden unos $30 \mathrm{~cm}$ de largo y los de abajo unos 22 $\mathrm{cm}$ de altura. Figure 5. Human-feline motifs on pieces from the Rosso collection. The upper ones are about $30 \mathrm{~cm}$ long and the bottom ones about $22 \mathrm{~cm}$ high.

categoría de imágenes abarca distintas combinaciones faunísticas, siendo el felino el animal más evocado en todas ellas (fig. 6).

En el repertorio iconográfico analizado no aparece representada la vida cotidiana/productiva. Fuera de la muestra, conocemos la existencia de algunas pocas representaciones de camélidos, especialmente de forma modelada en recipientes cerámicos. Sin embargo, la escasa frecuencia de su representación en la cerámica no es acorde con su predominio absoluto en el registro arqueofaunístico de los sitios estudiados. Lo mismo ocurre con los vegetales, considerando al respecto la interpretación de algunos motivos como plantas que proponen Marconetto (2015). Tampoco se representan objetos ligados a las actividades rutinarias de producción, uso y consumo, como serían los artefactos ligados a la agricultura, el pastoreo, el procesamiento y cocción de alimentos, etcétera.

$\mathrm{Al}$ considerar el modo de representación de los motivos figurativos y sus atributos compositivos, se destacan los siguientes aspectos (Gordillo 2009):

- La figura felínica es la que muestra mayor variación en términos de composición (ver fig. 2), siendo la actitud la variable más significativa. La vista (de perfil) es constante y la orientación se asocia estrechamente 

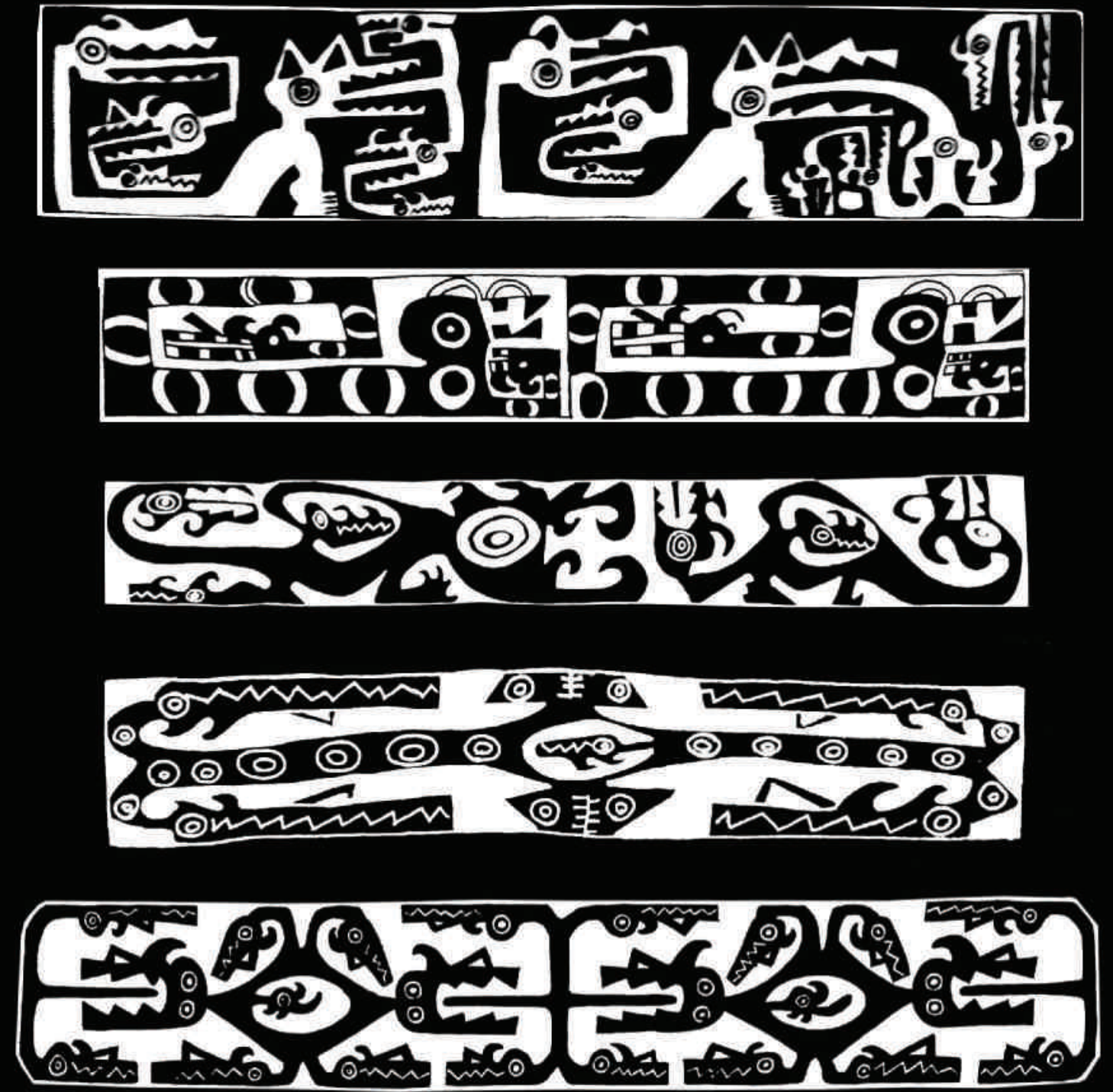

Figura 6. Figuras compuestas fantásticas grabadas. Corresponden a la colección Rosso, excepto la inferior que es del Museo Adán Quiroga de Catamarca. Largo de los diseños: $75 \mathrm{~cm}, 55 \mathrm{~cm}, 52 \mathrm{~cm}, 43 \mathrm{~cm}$ y $35 \mathrm{~cm}$, respectivamente. Figure 6. Engraved fantastical composite figures from the Rosso collection, except the bottom figure, which is from the Museum Adán Quiroga in Catamarca. Length of the designs: $75 \mathrm{~cm}, 55 \mathrm{~cm}, 52 \mathrm{~cm}, 43 \mathrm{~cm}$ and $35 \mathrm{~cm}$, respectively.

a la actitud. En función de ésta última, es posible definir tres clases de felino: erguido sobre sus patas, supino y sentado. Paralelamente es el único motivo que se combina con todos los demás.

- la figura humana mantiene constante sus atributos de composición: vista frontal, orientación vertical y actitud erguida (ver fig. 3). Cuando está acompaña- da de otros elementos, ocupa una posición central $\mathrm{y}$ es el único motivo que tiende a jerarquizar las composiciones, supeditando lateralmente referentes animales o materiales, como ocurre con la imagen del Sacrificador $(\mathrm{H})$ y la de su correlato compuesto, el enmascarado (HF). Este último, resulta de la sustitución de la cabeza antropomorfa por una felínica 


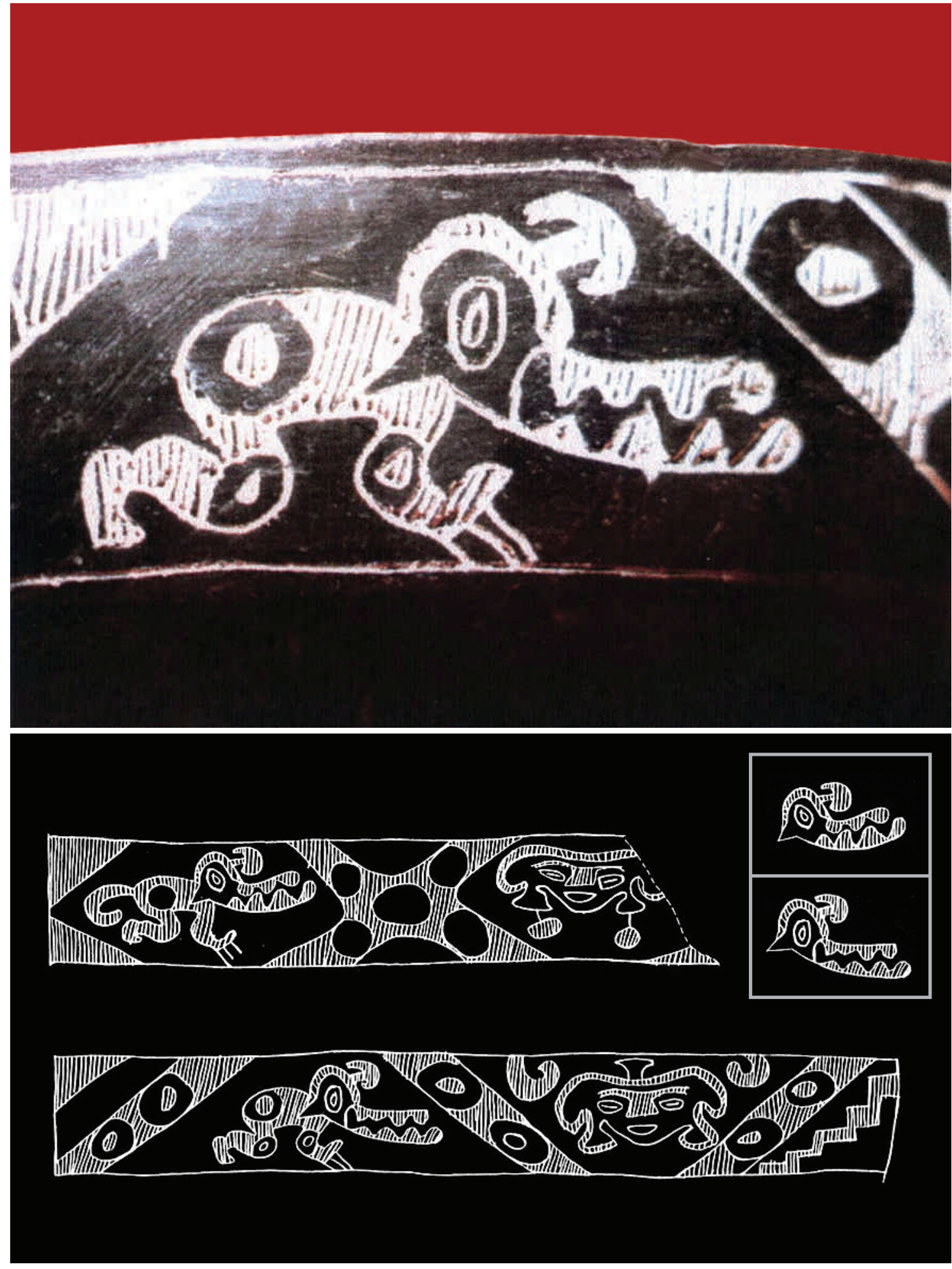

Figura 7. Figura ambigua que combina humano, felino y pájaro (6 cm de largo) en una escudilla de La Rinconada (E4). Figure 7. Ambiguous figure combining human, feline and bird features (6 cm long) on a bowl from La Rinconada (E4). 
Tabla 3. Atributos compositivos, distribución y combinación de los motivos simples. La x representa el motivo unidad y el subrayado señala la presencia de encuadre. Table 3. Compositional attributes, distribution and combination of simple motifs. The $\mathrm{x}$ represents the unit motif and the underline indicates the presence of framing.

\begin{tabular}{c|c|c|c|c|c|c}
\multirow{2}{*}{ MOTIVO } & VISTA & ORIENTACIÓN & ACTITUD & \multicolumn{2}{|c|}{ ESPACIOS COMPOSITIVOS } & COMBINACIÓN \\
\hline \multirow{2}{*}{ Felino } & Perfil & Horizontal & Supina & X-X & & FH y FF \\
\hline & Perfil & Horizontal & s/patas & X-X & XX-XX & FF, FZ, FO y FHOR \\
\hline & Perfil & Oblicua & s/patas & X-X & & FF y FF \\
\hline Humano & Perfil & Vertical & Sentada & X-X & & FH \\
\hline Ofidio & Aérea & Horizontal & $?$ & sXs-sXs & XX-XX & FFO y OO \\
\hline Ave & Frontal-Perfil & Vertical & Erguida & & XXXX-XXXX & FHOR \\
\hline Saurio & Aérea & Vertical & $?$ & X-X & & FSF
\end{tabular}

(máscara), sin perder por ello su identidad humana (ver fig. 4).

- Los motivos simples presentan formas recurrentes de representación (tabla 3) y son factibles de atomización y recombinación para formar figuras compuestas. Dentro de éstas, en la generación de motivos fantásticos se emplearon todos los procedimientos combinatorios antes mencionados: morfológica, actitudinal/ conceptual y, ambigüedad óptica-formal (fig.7).

En cuanto a las técnicas de ejecución, dentro de la muestra analizada para Ambato se distinguen:

- Grabado y/o incisión: ${ }^{4}$ se implementó casi exclusivamente en la alfarería reductora de superficies negras pulidas, pero en menor proporción incluye tonos grises y castaños. Algunos ejemplares presentan relleno de sustancia blanca que resalta el diseño, una aplicación post-cocción que pudo estar generalizada pero solo se conservó en unos pocos casos.

- Pintura: fue aplicada sobre las superficies pulidas o alisadas de la alfarería oxidante, antes de la cocción. Los colores empleados son el rojo, el negro y el blanco, combinándose frecuentemente estos dos últimos, los que sumados al color de fondo forman diseños bi y tricromáticos.

- Modelado: son aplicaciones al pastillaje, en cualquiera de las variantes tonales (series oxidante y reductora), combinado o no con otras técnicas de ejecución.
Mediante estás técnicas de ejecución, las formas se generan por contraste óptico y táctil en dos planos visuales -figura y fondo- frecuentemente reversibles. No existe la intención de representar mayor profundidad espacial a través de la perspectiva o de la superposición.

En los diseños pintados, el contraste de matiz y valor define formas en positivo, enteramente pintadas y/o delineadas en sus contornos, sobre el color de la superficie que siempre es el fondo de la composición.

Los motivos grabados/incisos son predominantes (fig. 8). Por lo general, también se delimitan linealmente y el plano de las figuras o del fondo -según sea en positivo o negativo- se diferencia por un rayado continuo. Se produce así el típico doble contraste de textura y de valor: áreas rayadas, rugosas y opacas en contraposición a las áreas lisas, suaves y pulidas; claras y oscuras, respectivamente (Gordillo 2009).

Los espacios compositivos (ver tabla 3) están sujetos a la morfología de la pieza. En la cerámica grabada, los diseños se despliegan sobre las superficies externas visualmente más accesibles, por encima del punto angular o mayor en las escudillas, cuencos y ollas, o bien en toda el área exterior de los recipientes cilíndricos. En las vasijas pintadas, se agregan otras posibilidades que involucran espacios mayores, incluyendo a veces todo el interior $\mathrm{y} / \mathrm{o}$ exterior de las vasijas abiertas. Considerando la delimitación explícita (encuadre) o no de campos compositivos, junto con la disposición de los motivos dentro de aquellos en cada pieza, se definen claramente dos tendencias dentro del universo cerámico de Ambato (Gordillo 2009): 


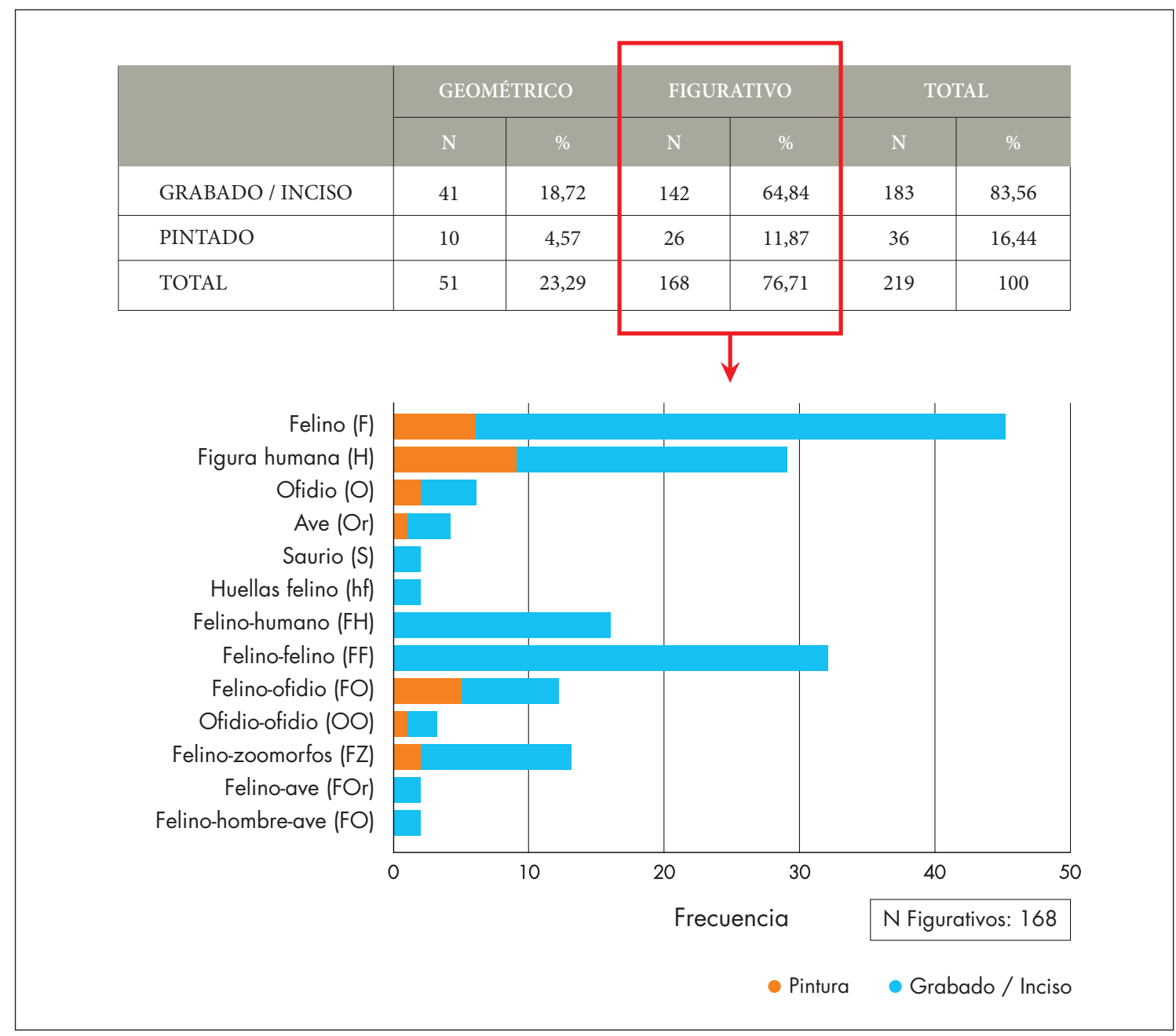

Figura 8. Recursos técnicos empleados en las representaciones de la cerámica de Ambato. Detalle a la derecha de los escogidos para resolver los motivos figurativos. Figure 8. Technical resources used to create the representations found on Ambato ceramics. On the right, details of the techniques chosen to make the figurative motifs.

- bandas horizontales, con motivos frecuentemente se repiten y definen una lectura rotativa del diseño. Es muy frecuente entre las escudillas grabadas, la clase de recipiente predominante en este el conjunto cerámico.

- ausencia de encuadres lineales, con un motivo único o repetido en campos visuales opuestos, a cada lado de la vasija. Dado que los límites del diseño solo están definidos por la morfología del recipiente, los motivos se despliegan con menos condicionantes espaciales que en el caso anterior. Si bien aparece en una variedad de vasijas, es común en las ollas con cuello de la cerámica fina.
Finalmente, al considerar dónde se representan estos diseños, reiteramos que la muestra Aguada aquí analizada incluye solo soportes cerámicos (escudillas, cuencos, ollas, vasos y tinajas), aunque de manera cualitativa también aludimos a sus correlatos con el arte rupestre de la sierra de Ancasti (fig. 9).

Como ya señalamos, una parte de la muestra corresponde a colecciones sobre las que poco o nada se sabe acerca de su contexto de hallazgo y asociaciones. Dado que son piezas enteras y con buen estado de conservación es probable que procedan de tumbas, pero hasta el momento son limitados los datos sobre los espacios funerarios del área y las ofrendas asociadas 

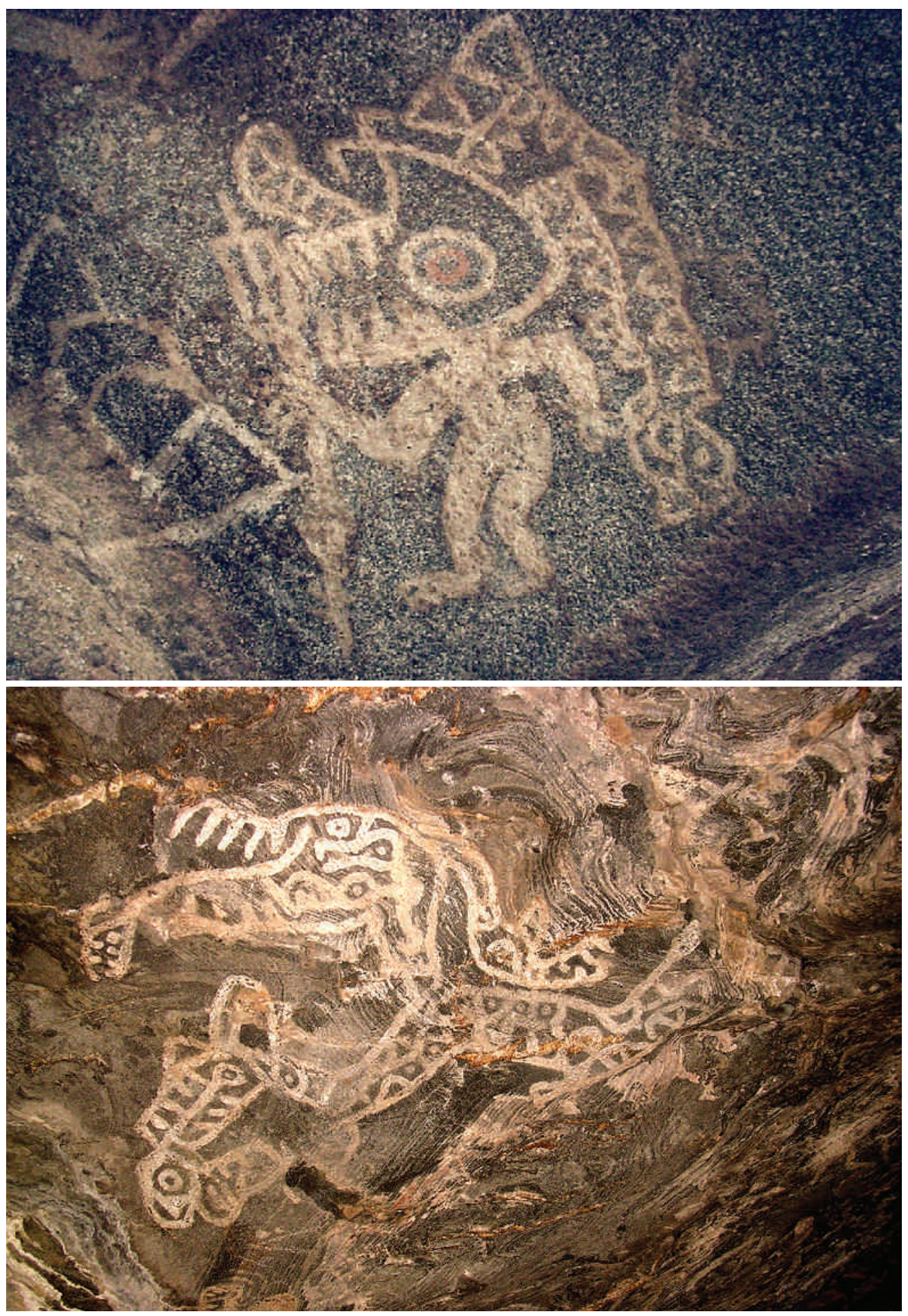

Figura 9. Motivos compuestos en la sierra de Ancasti: el "enmascarado" en La Sixtina (La Tunita) y una figura fantástica en La Candelaria. Miden $60 \mathrm{~cm}$ de alto y $112 \mathrm{~cm}$ de largo, respectivamente. Figure 9. Composite motifs from Sierra de Ancasti: the "masked one" in La Sixtina (La Tunita) and a fantastical figure in La Candelaria. The motifs measure $60 \mathrm{~cm}$ high and $112 \mathrm{~cm}$ long, respectively. 

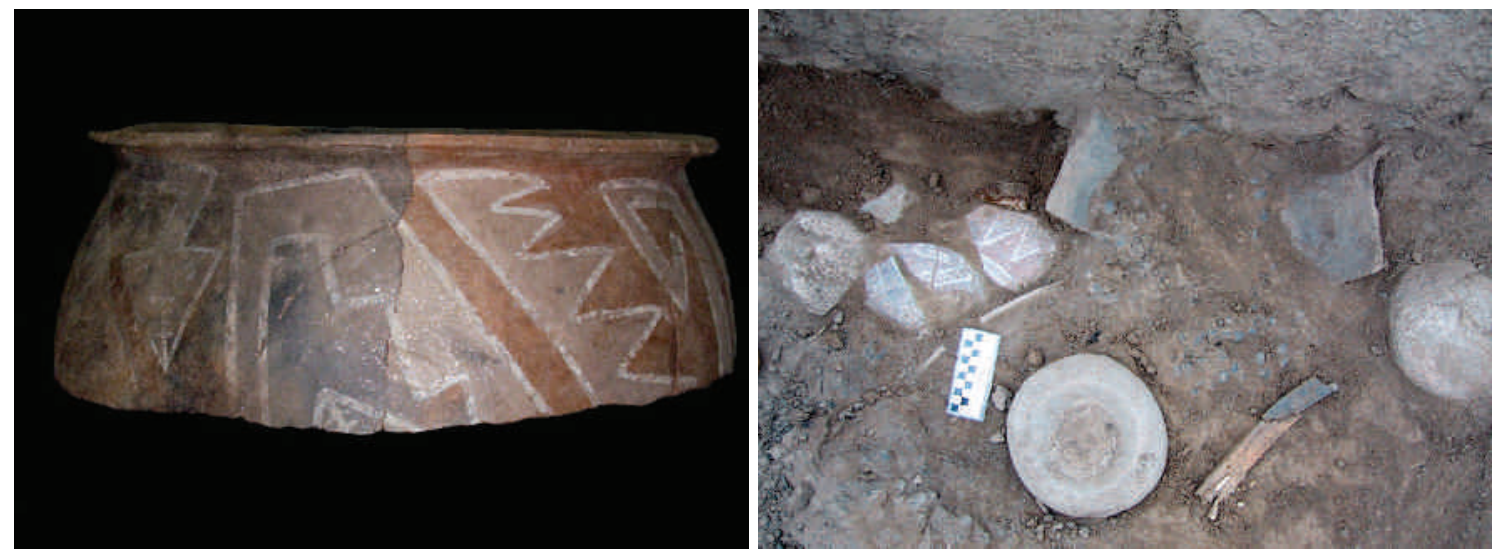

Figura 10. Diseño ofídico tricolor sobre el cuello recortado de una tinaja que funcionó como soporte de otra. A la derecha, los fragmentos de esa pieza y su contexto de hallazgo junto con semillas de chañar carbonizadas, huesos, morteros, etc., en el patio E5 de La Rinconada. Altura del cuello: $15 \mathrm{~cm}$. Figure 10. Tricolor snake design on the cutaway neck of a vessel that served as a support for another. Right, the fragments of that piece and the context of its discovery, in association with burnt chañar seeds, bones, mortars, etc., in patio E5 of La Rinconada. Neck height: $15 \mathrm{~cm}$.

(Gordillo \& Solari 2009, Cruz 2004). Afortunadamente, muchos de los materiales analizados fueron recuperados en excavaciones sistemáticas con registros precisos de su contexto de hallazgo, especialmente aquellos que proceden de la Iglesia de los Indios (La Rinconada).

A grandes rasgos, tales contextos corresponden, por un lado, a superficies de ocupación del área residencial y, por el otro, al relleno de estructuras macizas ligadas al espacio público (Gordillo 2004). En ambos contextos están representadas las dos principales modalidades estilísticas definidas para Aguada de Ambato.

Gran parte de los restos cerámicos y de otros materiales asociados habrían estado en uso activo o potencial en los antiguos pisos de las habitaciones y patios excavados durante los últimos momentos de la ocupación. Fueron destruidos, y en parte sellados, por el colapso de los techos quemados a causa de los incendios que marcan el final de la biografía del sitio (Gordillo \& Vindrola-Padrós 2017).

Respecto de la muestra alfarera, en el conjunto residencial se destaca un predominio de las grandes tinajas pintadas con motivos ofídicos en el patio E5 (fig. 10), las que se asocian estrechamente con el almacenamiento de frutos de chañar. En las demás estructuras habitacionales el predominio es de la cerámica negra grabada, pero con algunas variaciones en la clase de diseños y de motivos.

Por otro lado, los fragmentos cerámicos hallados en el interior macizo de la plataforma principal (E1) del sitio, corresponden básicamente a descarte secundario, es decir a materiales que fueron usados y desechados inicialmente en áreas domésticas y luego reutilizados como relleno de la estructura.

En síntesis, al considerar los contextos de vivienda de la mayoría de los materiales que conforman la muestra, resulta indiscutible que las representaciones aquí analizadas formaron parte la vida cotidiana a través de recipientes que sirvieron para preparar, consumir, guardar y ofrendar alimentos y otros productos. No podemos decir lo mismo para las piezas de colecciones, para las que no pueden definirse ni descartarse contextos funerarios como los que sí aparecen en universo tardío.

\section{El Período de Desarrollos Regionales en Fiambalá}

Dentro del repertorio desplegado en la cerámica Belén aquí analizada, son más frecuentes las imágenes geométricas (375: 510) que las figurativas (135: 510). Dentro de estas últimas predominan los motivos realistas simples (108: 135), específicamente las lechuzas (36: 135), seguidas de las vizcachas (22: 135), los ofidios y las huellas felínicas (18: 135, respectivamente). Las figuras compuestas (27: 135) más frecuentes son fantásticas y resultan de la combinación de atributos felínicos, aunque no haya representaciones de felino en soporte cerámico, con ofidios (F-O) y zoomorfos (F-Z) (25: 27). Los motivos compuestos realistas, al igual que en Aguada, son siempre 
FORMAS GEOMÉTRICAS
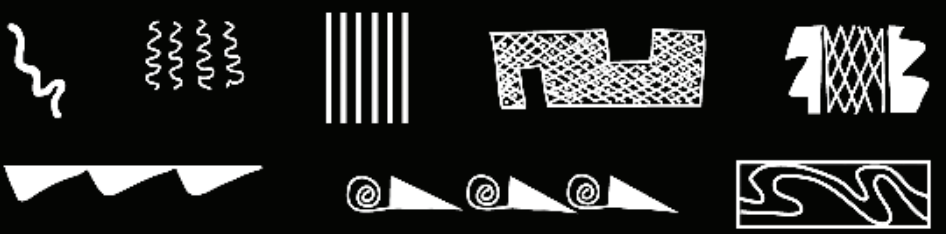

HUELLAS
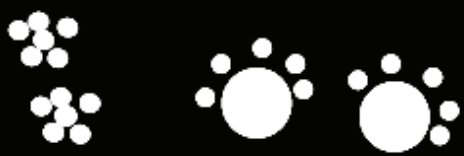

FIGURAS DE ANIMALES SIMPLES O COMPUESTAS
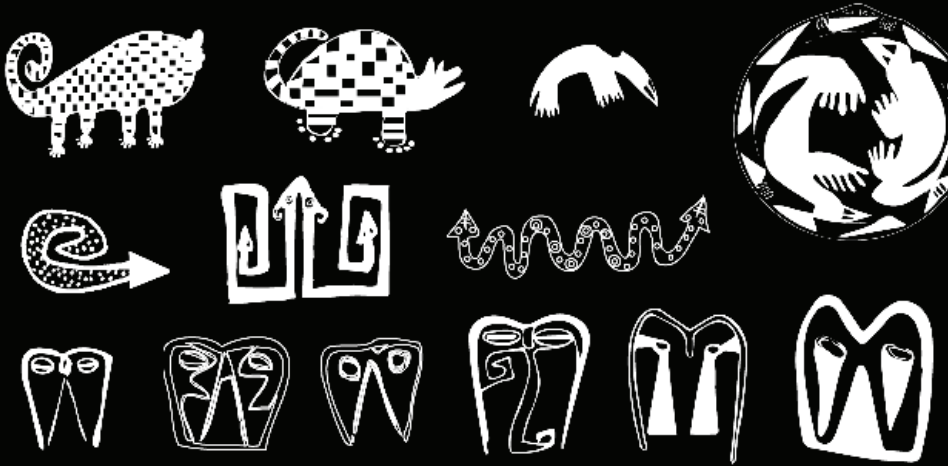

FIGURAS HUMANAS
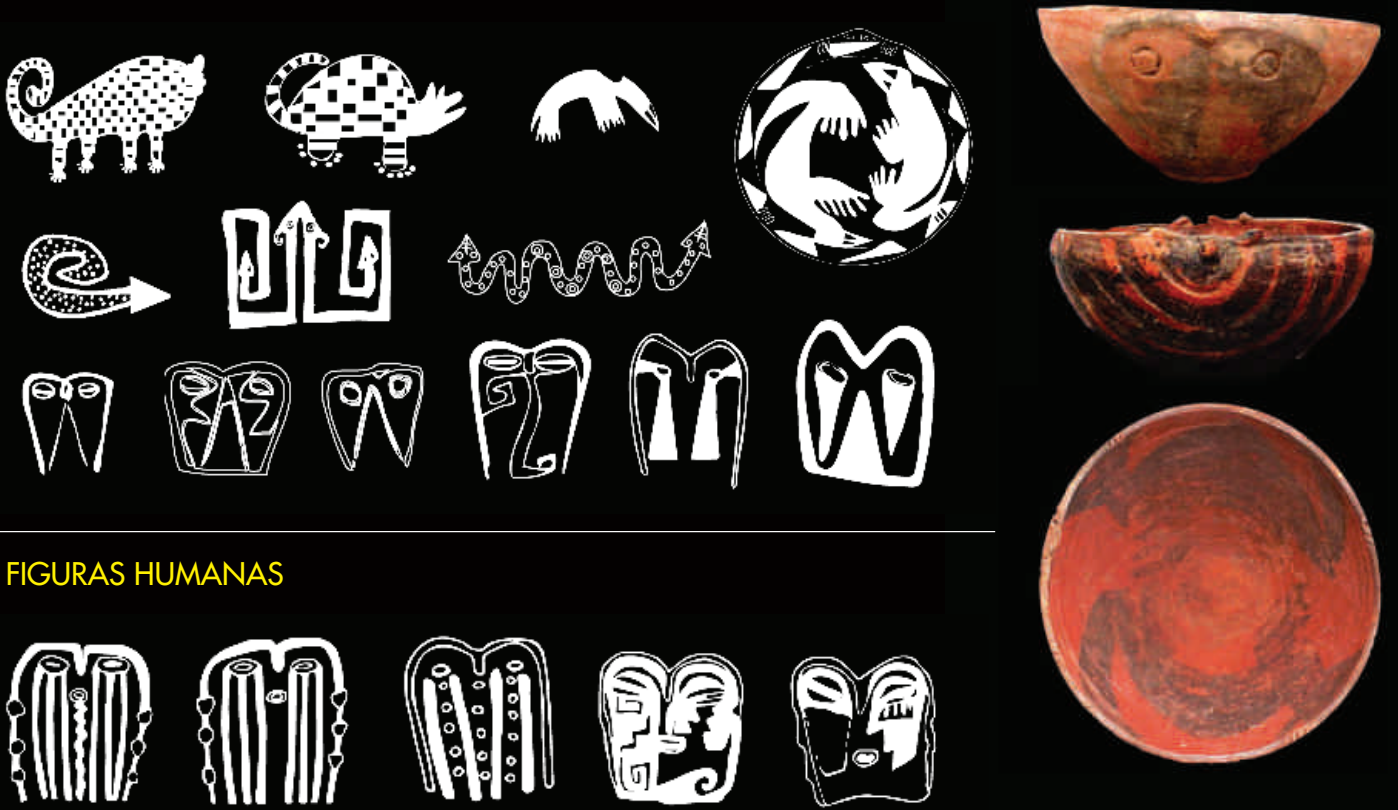

Figura 11. Repertorio temático registrado sobre los materiales cerámicos del PDR que conforman la muestra analizada. A la derecha, ejemplos de una pieza cerrada con huellas felínicas (arriba) - Istataco, Museo Jesuítico de Jesús María- y tres piezas abiertas con representaciones de lechuza, quirquincho y vizcachas (centro y abajo) -Finca Justo Pereira- (fotografías Pach-A). Figure 11. Thematic repertory recorded on ceramic materials of the PDR in the sample analyzed. On the right, examples of a closed vessel with feline footprints (above) -Istataco, Museo Jesuitico de Jesús María- and three open vessels with representations of owl, quirquincho and vizcachas (center and bottom) -Finca Justo Pereira- (photographs PAch-A).

antropo-felínicos (HF) pero son muy poco frecuentes (2: 135) (tabla 4 y fig. 11) (Ratto \& Basile 2013, Basile 2013b). Cabe destacar que aquí, si bien no se registran representaciones de camélidos o vegetales en este sopor- te, lo cotidiano no está completamente ausente ya que hay cierta cantidad de representaciones de vizcachas y, en menor medida, de quirquinchos. En función de la evidencia disponible estos dos animales eran, junto a los 
FORMAS GEOMÉTRICAS

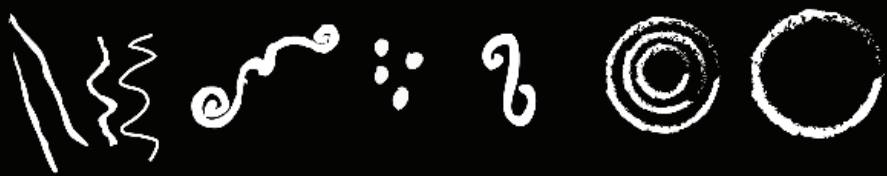

HUELLAS
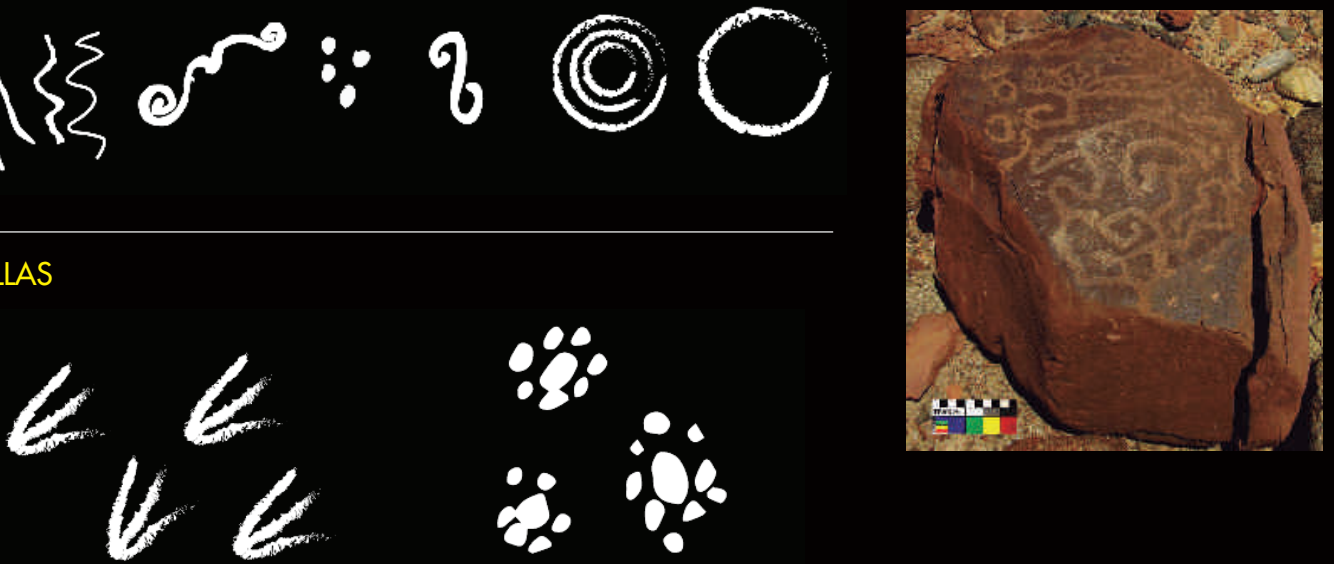

FIGURAS DE ANIMALES SIMPLES O COMPUESTAS
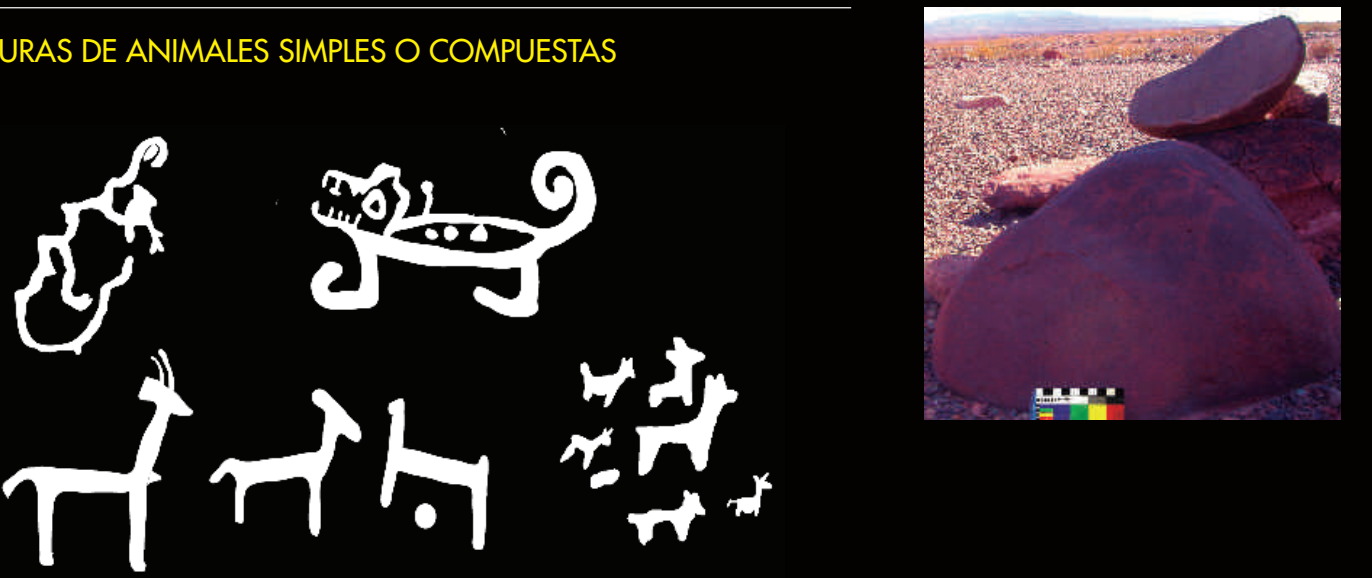

FIGURAS HUMANAS
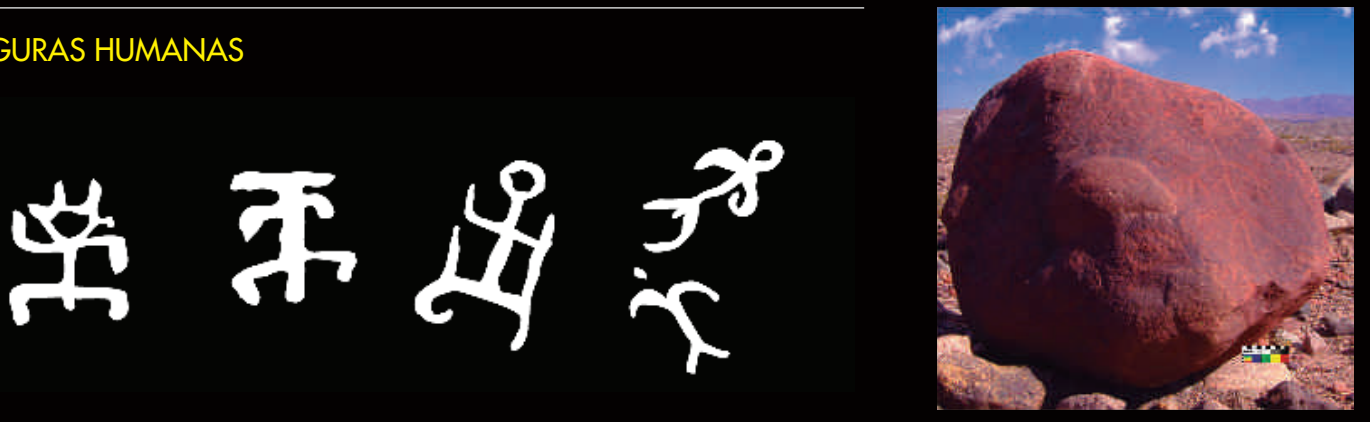

Figura 12. Repertorio temático registrado sobre los bloques grabados del sitio Guanchincito que conforman la muestra analizada. A la derecha, ejemplos del único felino registrado -bloque v-, los camélidos -bloque IX- y una figura humana -bloque III- (adaptado de Basile \& Ratto 2014) (fotografías PAch-A). Figure 12. Thematic repertory registered on the engraved blocks at Guanchincito site in the sample analyzed. On the right, examples of the only feline registered -block V-, camelids-block IX-and a human figure-block III-(adapted from Basile and Ratto 2014) (photographs PACh-A-). 
Tabla 4. Repertorio temático registrado en los soportes cerámicos y rupestres considerados para el Período de Desarrollos Regionales de la Región de Fiambalá. Table 4. Thematic repertory recorded on ceramic and rock supports examined for the Regional Developments Period in the Fiambalá Region.

\begin{tabular}{|c|c|c|c|c|c|c|c|c|c|c|}
\hline \multirow{3}{*}{\multicolumn{2}{|c|}{$\begin{array}{l}8 \\
\sum \\
\Sigma\end{array}$}} & & \multicolumn{5}{|c|}{ SOPORTE CERÁMICO } & \multicolumn{3}{|c|}{ SOPORTE RUPESTRE } \\
\hline & & & \multirow[t]{2}{*}{ TOTAL } & \multirow{2}{*}{$\begin{array}{c}\text { FIGURACIÓN } \\
(\%)\end{array}$} & \multirow{2}{*}{$\begin{array}{l}\text { FIGURACIÓN } \\
\text { GEO. }(\%)\end{array}$} & \multicolumn{2}{|c|}{ FORMAS } & \multirow[t]{2}{*}{ TOTAL } & \multirow{2}{*}{$\begin{array}{l}\text { FIGURACIÓN } \\
(\%)\end{array}$} & \multirow{2}{*}{$\begin{array}{c}\text { FIGURACIÓN } \\
\text { GEO. (\%) }\end{array}$} \\
\hline & & & & & & A & C & & & \\
\hline \multirow{10}{*}{$\frac{\mathscr{s}}{\stackrel{2}{\Xi}}$} & \multirow{11}{*}{ 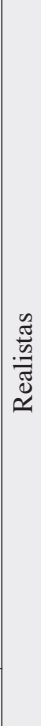 } & Figuras Humanas $(\mathrm{H})$ & 6 & 4,44 & & & $\mathrm{x}$ & 18 & 33,96 & \\
\hline & & Ave (A) & 36 & 26,68 & & $\mathrm{x}$ & $\mathrm{x}$ & 1 & 1,89 & \\
\hline & & Ofidio $(\mathrm{O})$ & 18 & 13,33 & & $\mathrm{x}$ & $\mathrm{x}$ & & & \\
\hline & & Quirquincho $(\mathrm{Q})$ & 4 & 2,96 & & $\mathrm{x}$ & & & & \\
\hline & & Vizcacha/zoomorfos (Z) & 22 & 16,30 & & $\mathrm{x}$ & & 1 & 1,89 & \\
\hline & & Saurios (S) & 4 & 2,96 & & & $\mathrm{x}$ & & & \\
\hline & & Huellas de felino & 18 & 13,33 & & & $\mathrm{x}$ & 5 & 9,43 & \\
\hline & & Huellas de ave & & & & & & 12 & 22,64 & \\
\hline & & Felino (F) & & & & & & 1 & 1,89 & \\
\hline & & Camélidos (C) & & & & & & 14 & 26,42 & \\
\hline \multirow{5}{*}{ 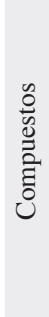 } & & Felino-H (HF) & 2 & 1,48 & & & $\mathrm{x}$ & 1 & 1,89 & \\
\hline & \multirow{4}{*}{ 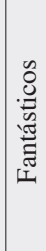 } & Felino-zoomorfos (F-Z) & 12 & 8,89 & & $\mathrm{x}$ & $\mathrm{x}$ & & & \\
\hline & & Felino-ofidio (FO) & 10 & 7,41 & & & $\mathrm{x}$ & & & \\
\hline & & Ofidio-ofidio (OO) & 2 & 1,48 & & & $\mathrm{x}$ & & & \\
\hline & & Ave-ofidio (AO) & 1 & 0,74 & & $\mathrm{x}$ & & & & \\
\hline \multicolumn{3}{|c|}{ Total figurativos } & 135 & 100 & 26,5 & & & 53 & 100 & 29,94 \\
\hline \multicolumn{3}{|c|}{$\begin{array}{l}\text { Total geométricos } \\
\text { (Hoyuelos, Trazos, } \\
\text { Escalonados y Circulares) }\end{array}$} & 375 & & 73,5 & $\mathrm{x}$ & $\mathrm{x}$ & 124 & & 70,06 \\
\hline \multicolumn{3}{|c|}{ TOTAL figurativos y geométricos } & 510 & & & & & 177 & & \\
\hline
\end{tabular}

camélidos, consumidos frecuentemente en momentos previos (Miyano 2017) y contemporáneos (Belotti 2015).

En los grabados rupestres del sitio Guanchincito (GCH) también son más frecuentes los motivos nofigurativos (124: 177/70.06\%) que los figurativos (53: $177 / 29,94 \%)$ y aquí el predominio de los motivos realistas simples es casi absoluto (52: 53). Pero entre ellos, a diferencia de lo que ocurre en el soporte cerámico, lo más frecuentemente representado son las figuras humanas (18: 53), seguidas de los camélidos (14: 53), las huellas de aves (12: 53) y las de felino (5: 53). Además, en este soporte se registra el único felino de la muestra tardía (tabla 4 y fig. 12).

El recurso técnico elegido para la mayor parte de las representaciones realizadas sobre cerámica es la aplicación de pintura de color negro que, al combinarse 


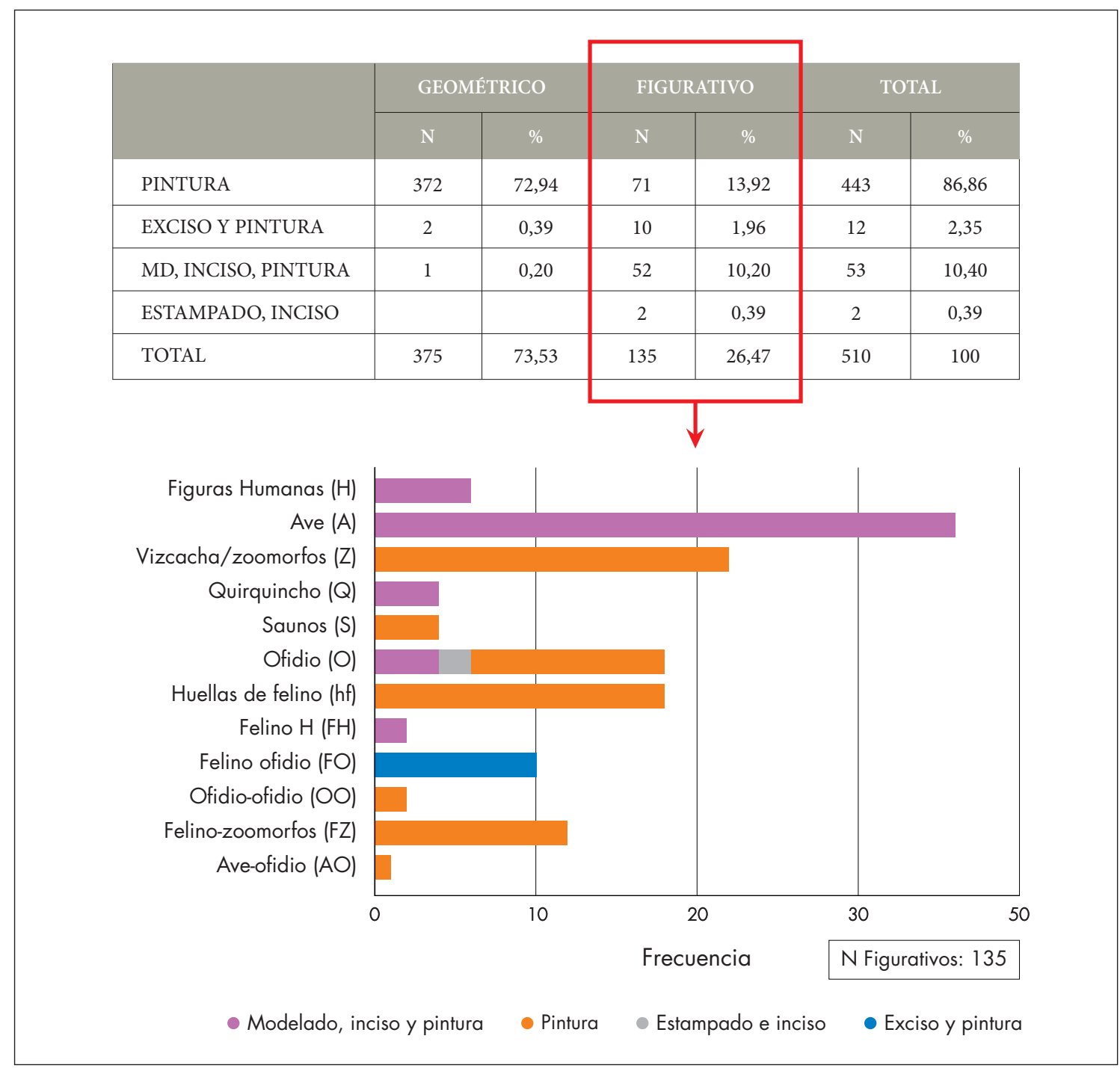

Figura 13. Recursos técnicos empleados en las representaciones desplegadas en la cerámica del PDR. Detalle a la derecha de los escogidos para resolver los motivos figurativos. Figure 13. Technical resources used to create representations found on PDR ceramics. On the right, details of the techniques chosen to make the figurative motifs.

con el rojo de la superficie de la pieza, conforma diseños bicromáticos por contraste de matiz y valor, aunque también hay combinaciones de técnicas que definen formas por matiz, valor y textura (pintura y exciso o pintura modelado e inciso). Los motivos geométricos y las huellas felínicas se resuelven fundamentalmente mediante la pintura en negro sobre rojo. Las figuras ofídicas tienden a realizarse por medio de la pintura, pero presentan diversidad, en algunos casos se suma el estampado, en otros el inciso y el modelado. Es interesante destacar que los ofidios felinizados siempre se ejecutan por medio del exciso junto con la pintura y esta combinación no se utiliza para el resto de los ofidios no felinizados. Las vizcachas y zoomorfos felinizados se pintan y para los quirquinchos (4: 25) se suma, además, el inciso y el modelado. Las lechuzas, las figuras humanas y la figura humana felinizada solo se realizan por medio de la combinación de la pintura junto con el modelado y el inciso. Son, en consecuencia, los únicos que adquieren características "tridimensionales" y policromas y son definidos por contrastes ópticos y táctiles de matiz, valor y textura (fig. 13). 
Tabla 5. Atributos de composición empleados en los motivos simples analizados del PDR de la región de Fiambalá, los soportes en los que se registran y los motivos a los que se asocian. En la distribución en soporte cerámico la "X" representa el motivo simple, la "s" a los otros motivos a los que puede estar asociado y el subrayado la presencia de encuadre. Table 5. Compositional elements used for the simple motifs analyzed in the PDR of Fiambala region, the supports on which they were recorded, and associated motifs. The " $X$ " represents the simple motif and the " $\mathrm{s}$ " the other motifs with which it may be associated, while the underline indicates the presence of framing.

\begin{tabular}{|c|c|c|c|c|c|c|c|c|}
\hline \multirow[t]{2}{*}{ MOTIVO } & \multicolumn{3}{|c|}{ ATRIBUTOS DE COMPOSICIÓN } & \multicolumn{2}{|c|}{ SOPORTE } & \multicolumn{2}{|c|}{$\begin{array}{l}\text { DISTRIBUCIÓN EN } \\
\text { SOPORTE CERÁMICO }\end{array}$} & \multirow[t]{2}{*}{$\begin{array}{l}\text { COMBINACIONES } \\
\text { REGISTRADAS }\end{array}$} \\
\hline & VISTA & ORIENTACIÓN & ACTITUD & $\mathrm{C}$ & $\mathbf{R}$ & $\begin{array}{l}\text { SUPERIOR } \\
\text { EXTERIOR }\end{array}$ & $\begin{array}{l}\text { SUPERIOR } \\
\text { INTERIOR }\end{array}$ & \\
\hline $\begin{array}{l}\text { Huellas de felino } \\
\text { o de ave }\end{array}$ & ?? & ?? & ?? & $\sqrt{ }$ & $\sqrt{ }$ & sXs-sXs & - & Zoomorfos \\
\hline \multirow[t]{2}{*}{ Lechuzas } & \multirow[t]{2}{*}{ Frontal } & \multirow[t]{2}{*}{ Vertical } & \multirow[t]{2}{*}{ Erguida } & \multirow[t]{2}{*}{$\sqrt{ }$} & & $\underline{\text { sXs-sXs }}$ & - & \multirow[t]{2}{*}{ Ofidio } \\
\hline & & & & & & $\underline{\mathrm{X}-\mathrm{X}-\mathrm{X}}$ & - & \\
\hline Suri & Perfil & Vertical & Erguida & & $\sqrt{ }$ & & & - \\
\hline Ofidios & Aérea & & & $\sqrt{ }$ & $\sqrt{ }$ & $\mathrm{X}-\mathrm{X}$ & - & Felino - Ofidio \\
\hline Figuras Humanas & Frontal & Vertical & Erguida? & $\sqrt{ }$ & $\sqrt{ }$ & sXs-sXs & - & Felino \\
\hline Quirquincho & Perfil & Horizontal & Supina & $\sqrt{ }$ & & $\mathrm{X}$ & - & - \\
\hline Vizcachas/ Zoomorfos & Perfil & Horizontal & s/patas & & & & $\mathrm{X}-\mathrm{X}$ & Felino \\
\hline Felino (F) & Perfil & Horizontal & s/patas & & $\sqrt{ }$ & & & H-Zoomorfos \\
\hline Camélidos (C) & Perfil & Horizontal & s/patas & $\sqrt{ }$ & $\sqrt{ }$ & & & - \\
\hline Saurios & Aérea & Horizontal & s/patas & $\sqrt{ }$ & & $\underline{X-X}$ & - & - \\
\hline
\end{tabular}

En el caso del arte rupestre, todas las imágenes aquí analizadas fueron realizadas por medio de la técnica de piqueteado superficial a partir de la cual se despeja parte de la corteza de la roca generando un contraste de textura y valor que genera siempre figuras en positivo.

A partir de estos recursos técnicos se configuran, en ambos soportes, dos planos visuales en los que las figuras se despliegan sobre el fondo. Se han registrado casos de reversibilidad únicamente en soporte cerámico y en el caso de ciertos motivos geométricos (escalonados) y en algunas figuras ofídicas felinizadas y no felinizadas que son estructuralmente semejantes a ellos (fig. 14, centro).

Es interesante destacar que, más allá de las particularidades que distinguen a cada uno de estos soportes no solo en términos de materia prima y técnicas expresivas sino también de dimensiones, visibilidad, movilidad y localización en el paisaje, los atributos de composición empleados en la representación de las imágenes desplegadas en ellos son semejantes entre sí y con el universo Aguada. La animalidad, tanto en roca como en cerámica, se representa de perfil y en forma horizontal, salvo las lechuzas que se representan de frente y en orientación vertical al igual que la figura humana y la F-H. La otra excepción a esta regla es el caso de los ofidios y saurios cuya vista es siempre aérea. El caso de las huellas (de felino o de ave) es de más esquiva categorización ya que si bien la actitud podría inferirse porque la mera representación de la huella implica que el animal estaba erguido sobre sus patas, clasificarlas en términos de actitud y orientación resulta complicado (tabla 5).

Si enfocamos específicamente el caso de las figuras compuestas, que son prácticamente exclusivas del soporte cerámico ya que en roca registramos un único caso, vemos que, tal como sucede en el universo Aguada, los atributos 


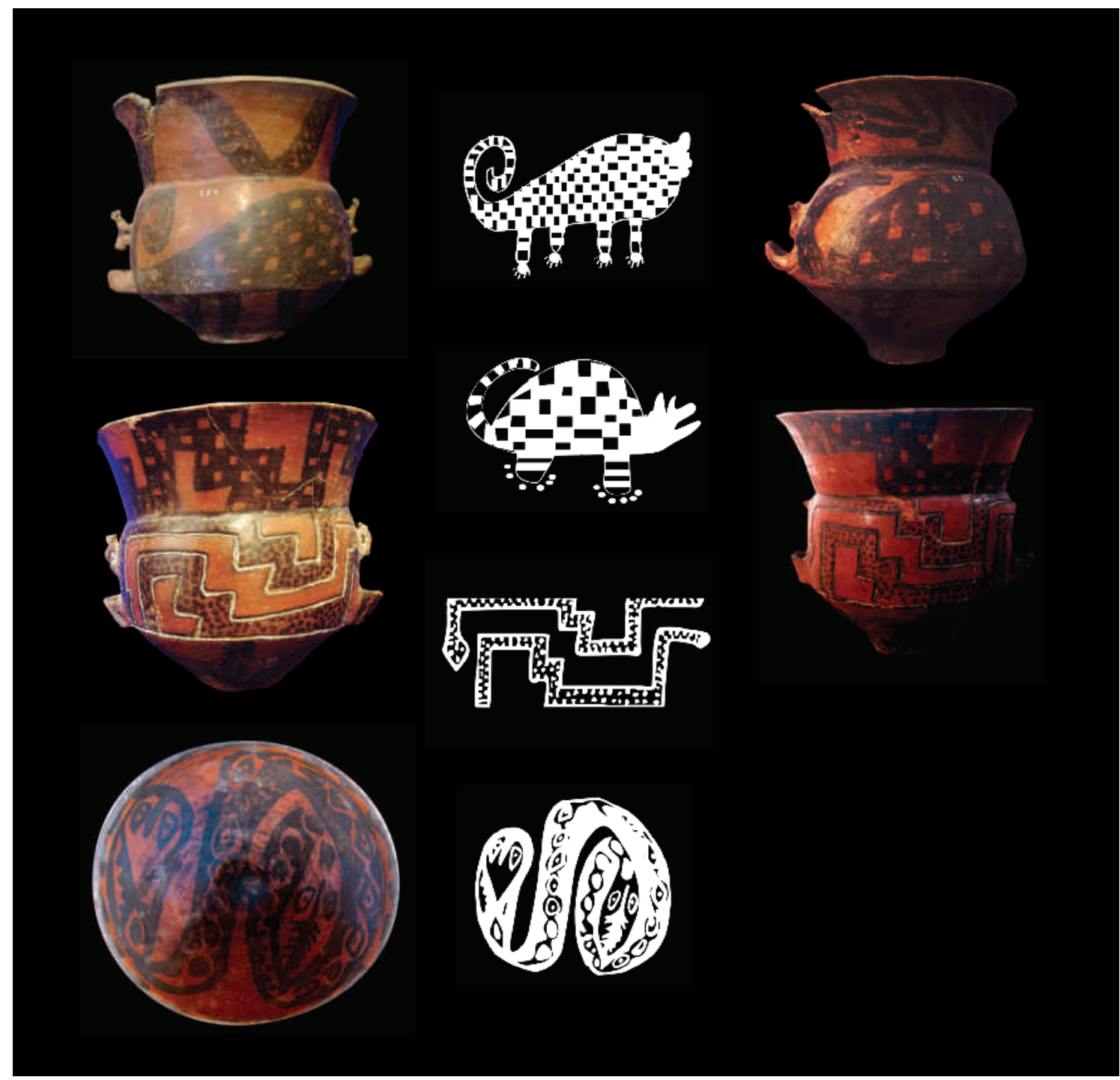

Figura 14. Ejemplos de figuras compuestas de la cerámica Belén del PDR conformadas por combinación morfológica. Arriba: zoomorfos felinizados -Huanchín, Museo Inca huasi-. Centro: ofidios felinizados -Huanchín, Museo Incahuasi y Fiambalá, Museo del Hombre-. Abajo: ave-ofidio - Las Champas, Colección Bayón- (fotografías PAch-A). Figure 14. Examples of composite figures in Belén ceramics of the PDR formed by morphological combination. Top: feline zoomorphs-Huanchin, Museo Incahuasi-. Center: feline-snakes -Huanchin, Museo Incahuasi y Fiambalá, Museo del Hombre-. Bottom: bird-snake -Las Champas, Colección Bayón-(photos: PAch-A).

de composición de cada uno de los motivos siempre se mantienen en la combinación. Para la construcción de estas figuras se ponen en acto dos procedimientos compositivos. Por un lado, todas las figuras compuestas se conforman a partir de la combinación morfológica a partir de la cual se integran fundamentalmente atributos felínicos (fauces, manchas garras, huellas) con partes de otros animales $y$, en menor medida, partes de distintos animales (ave-ofidio) (ver fig. 14).
Por otro lado, hay una serie de imágenes que construyen un sentido dual a partir de la combinación de atributos conceptuales o actitudinales, específicamente las lechuzas, las figuras humanas y el humano felinizado desplegados en cerámica apelan a la ambigüedad a partir de la semejanza en su resolución en términos de tamaño, recursos técnicos, atributos de composición y posición en formas de piezas comunes (fig. 15) (Ratto \& Basile 2013). 


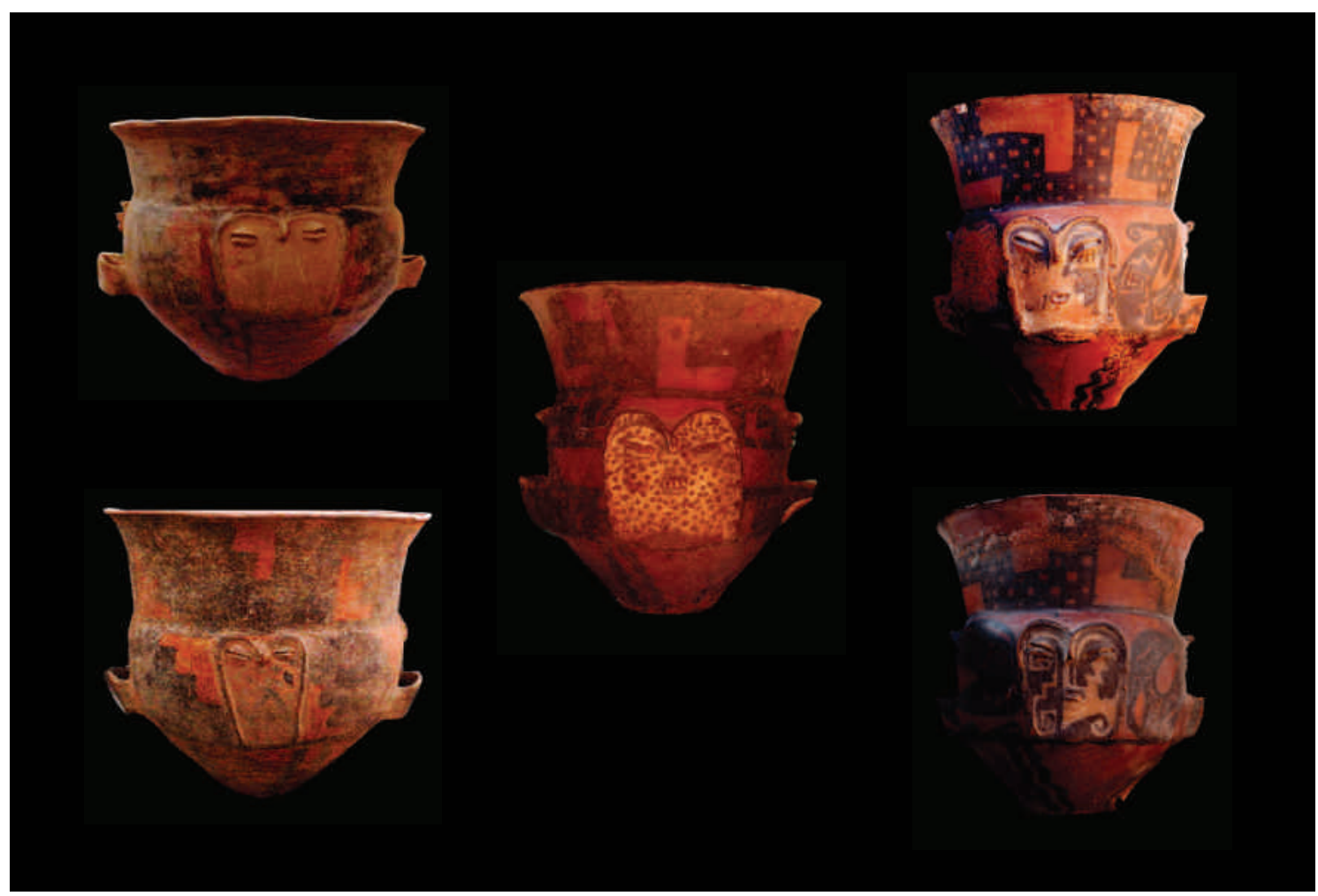

Figura 15. Ejemplos de figuras compuestas de la cerámica Belén del PDR conformadas por combinación de atributos conceptuales. Izquierda: representaciones de lechuzas -Finca Justo Pereira-. Centro: figura humano-felínica -Las Champas, extraída de Ratto y Basile 2013, fig. 17-. Derecha: representaciones de figuras humanas -Fiambalá, Museo del Hombre- (fotografías PAch-A). Figure 15. Examples of composite figures on Belén ceramics of the PDR formed from a combination of conceptual elements. Left: representations of owls -Finca Justo Pereira-. Center: human-feline figure -Las Champas, taken from Ratto and Basile 2013, fig. 17-. Right: human figures -Fiambalá, Museo del Hombre- (photos: PAch-A).

Si nos centramos específicamente en los lugares de representación de las imágenes analizadas nos enfrentamos por un lado a los soportes, bloques y piezas cerámicas, y, por el otro, a los contextos de los que estos materiales y las imágenes en ellos desplegadas participan. Observamos que, en el caso de los materiales cerámicos, las imágenes se despliegan sobre piezas cerradas compuestas o inflexionadas y sobre piezas abiertas simples o compuestas. En el caso de las primeras, las imágenes desplegadas en el espacio plástico interno suelen limitarse solo al borde, mientras que el externo tiende a encontrarse segmentado en tres campos horizontales diferenciados por el trazado de una línea divisoria de color negro y espesor variable. Estas unidades tienden a coincidir exactamente con la ubicación de los puntos angulares o de inflexión que marcan, a lo largo del contorno, las porciones formales en que estas piezas pueden descomponerse: cuerpo inferior, cuerpo superior y cuello (Bregante 1926, Wyndveldt 2007, Basile 2012, entre otros). En contraste, en el caso de las piezas abiertas, las imágenes suelen extenderse tanto en la superficie externa que puede encontrarse o no segmentada en dos campos horizontales, como en la totalidad de la superficie interna. Cada uno de estos campos presenta dimensiones, motivos y recursos compositivos particulares. Se han documentado asociaciones entre ciertos tipos de motivos y ciertas formas abiertas o cerradas de piezas cerámicas: (i) las huellas $y$ las figuras humanas son exclusivas de las superficies de las piezas cerradas; (ii) compuestos y figuras ofídicas tienden a estar más frecuentemente desplegados en las piezas cerradas mientras que (iii) los quirquinchos $y$ vizcachas son más frecuentes en las piezas abiertas; $y$ (iv) las lechuzas se presentan con frecuencias similares tanto en piezas abiertas como en piezas cerradas (ver tabla 5). ${ }^{5}$ Las posibilidades de distribución de estos 
motivos en los campos de diseño internos o externos de las piezas cerámicas se sintetizan en la tabla 5 . De su lectura se desprende que allí donde los motivos figurativos aparecen, independientemente de la forma abierta $o$ cerrada de la pieza soporte, se impone la dualidad como elemento compositivo y observamos cómo el campo se segmenta en paneles contrapuestos pero de contenido equivalente. En el caso de las piezas abiertas, los motivos figurativos se ubican en el exterior de forma sucesiva o en el interior de forma tal que la cabeza de un personaje "mira" hacia la cola del otro y viceversa. Por su parte, en el caso de la superficie externa de las piezas cerradas, el ordenamiento del motivo central y los laterales se repite en forma exacta en el lado diametralmente opuesto de la pieza. Cabe destacar particularmente que la figura humana, las lechuzas y la F-H imponen jerarquía en la composición presentándose siempre como motivos únicos o, en el caso de estar acompañados de otros diseños, estos últimos siempre ocupan los lugares secundarios.

En este punto, las imágenes grabadas de $\mathrm{GCH}$ plantean un desafío en términos de la organización en cada bloque como espacio compositivo. Coincidimos con Gallardo (2009) y consideramos que podrían pensarse en términos de disposiciones, agregados cuya expresión visual resulta de actos sucesivos en los que las imágenes se suman, entablan sin duda un diálogo entre sí, con las realizadas previamente quizás por otras manos, pero parecen agregarse de forma aleatoria. En este caso, las imágenes figurativas no imponen una jerarquía en estas disposiciones, sino que se ubican junto a otros motivos figurativos o geométricos en tamaños semejantes y ocupando lugares diversos, no necesariamente centrales. Aquí, la norma de la unidad parece residir en el agregado de las distintas imágenes de manera aparentemente no equilibrada (a nuestros ojos), donde la intención parece estar depositada en guardar el registro de esas intervenciones sucesivas en un tiempo difícil de precisar, un mensaje que estaba disponible para quien compartiera el código que hoy desconocemos.

Respecto de los contextos, es necesario volver a destacar que los materiales cerámicos del PDR proceden fundamentalmente de contextos funerarios, aunque no podemos descartar que esos mismos materiales hayan formado parte, previamente, de contextos domésticos. ${ }^{6}$ Lo cierto es que, la mayor parte de ellos fueron recuperados en excavaciones sistemáticas, en el marco de rescates arqueológicos o asistemáticas y hoy conforman colecciones que están en manos de pobladores locales o se encuentran depositadas en instituciones museográficas. Por su parte, las imágenes grabadas en los bloques del sitio Guanchincito están asociadas a una de las rutas que conectan distintos pisos altitudinales en dirección sur-norte-sur dentro de las tierras bajas del valle, pero también están vinculadas a tres entierros y a una vasta extensión de campos de cultivo (Ratto et al. 2000-2002). Por lo tanto, la producción de estas imágenes grabadas estaba conectada con otras actividades cotidianas como el cuidado de los cultivos, la producción de alimentos y el entierro de difuntos (Orgaz \& Ratto 2012, Basile \& Ratto 2014).

Independientemente del contrapunto existente entre estos soportes y los contextos que define y de los que participa cada uno, existen ciertos elementos semejantes que residen fundamentalmente en el predominio de las imágenes geométricas, un repertorio particular de imágenes figurativas entre las que predominan los motivos simples (con frecuencias, tendencias y formas de representación diferentes en cada caso) y la puesta en acto de los mismos recursos compositivos para generar las representaciones de estas imágenes simples y sus combinaciones.

\section{DISCUSIÓN Y CONCLUSIONES}

El ejercicio que hemos realizado nos permitió detectar divergencias y también de paralelismos entre los dos universos expresivos considerados:

\section{a) Las divergencias}

- Predominio de motivos figurativos sobre los geométricos en Aguada de Ambato (AA), situación que se invierte en Belén de Fiambalá (BF).

- Felino simple dominante en AA y ausente en BF, solo presente en el arte rupestre de GCH.

- Representación significativa de la figura humana en AA.

- Representación significativa de lechuzas en BF.

- La variedad de motivos simples es mayor en BF, como también el número de motivos por pieza.

- Presencia de figuras fantásticas en AR Aguada, prácticamente ausentes en AR Tardío.

- Paridad entre motivos simples y compuestos en AA y predominio de los motivos simples en $\mathrm{BF}$. 
- Mayor variedad de técnicas en BF.

- Tendencia a la asociación motivo-forma en BF.

- En AA todos los casos de recursos compositivos combinación por ambigüedad óptica o formal.

- Pocas escenas en AA, ausentes en BF y en el AR Tardío.

- Diferentes tipos de contextos.

- Mayor variedad de colores de fondo resultantes de distintas atmósferas de cocción en AA.

Ausencia de formas en negativo en Belén.

\section{b) Los paralelismos}

- Espacios compositivos definidos por la morfología de la pieza o por campos delimitados dentro de la misma.

- El repertorio iconográfico consta de referentes humanos y animales, y sus índices.

- Los motivos compuestos realistas son siempre antropofelínicos (HF).

- Poco o nada de camélidos en AA y BF, presentes en AR Tardío.

- El felino es el más combinado.

- La figura humana introduce jerarquía en la composición en soporte cerámico.

- Atributos de composición son semejantes y se mantienen en la combinación.

- Se manejan uno o dos planos de profundidad.

- Uso de figura-fondo reversible (frecuente en AA y presente pero escaso en $\mathrm{BF}$ ).

- Creación de figuras compuestas por combinación morfológica y por actitud o atributos conceptuales.

Este ensayo comparativo no tuvo como objetivo trazar relaciones históricas entre los dos universos expresivos, sino conocer con mayor profundidad cada uno de ellos. Esto nos permitió, entre otras cosas, cuestionar categorías que, definidas para cada uno en forma independiente, al ser puestas a prueba aplicándolas al otro universo demandaron reformulaciones. Por ejemplo, la creación de ambigüedad en Belén a partir de elementos distintos a los usados para crearla en Aguada, ya que se emplean atributos conceptuales que colocan a ciertos motivos $(\mathrm{H}$, Lechuza y F-H) en posiciones semejantes o equivalentes en términos de posición formal, atributos de vista y actitud, formas de contraste (técnicas).

También nos obligó a repensar la composición a nivel de contexto, ya que, si bien la construcción de escenas es propia del universo Aguada, la ausencia de narrativas a nivel de piezas no necesariamente implica que no las haya a un mayor nivel, el de la combinación de piezas con diseños diversos participando juntas de los mismos contextos. Podemos pensar en la creación de composiciones abiertas funcionando a otros niveles, donde las relaciones espaciales y conceptuales entre motivos se puedan dar entre piezas diferentes. Así, las historias podrían construirse y narrarse a partir de las combinaciones que se den no solo dentro de cada pieza sino también entre piezas. En el caso del arte rupestre de Guanchincito, donde tampoco hay construcción de escenas, bien podría haber habido un recorrido que vinculara los distintos motivos ubicados en diferentes bloques quizás guiado por un narrador.

El ejercicio nos condujo además a reconocer que la variedad de motivos simples es mayor en Belén. En Aguada, la figura del felino es dominante y es la única que se combina con todas las demás. Por su parte, la figura humana es también muy frecuente y es la única que puede introducir la jerarquía en la composición, asociándose a elementos artefactuales y animales. En Belén el felino está ausente como figura simple, pero es la que genera la mayor parte de las figuras compuestas fantásticas o realistas y son la lechuza, junto a la figura humana y la figura humana felinizada, las que introducen una jerarquía en la composición ocupando siempre lugares centrales y no apareciendo nunca como motivos secundarios. Resulta sugestiva también la gran cantidad de representaciones de animales felinizados dentro del repertorio cerámico del PDR, reproduciendo el carácter y las propiedades combinables del símbolo felínico de Aguada y tal vez de ciertos relatos y creencias asociadas a esos discursos visuales.

El trabajo nos permitió ratificar, además, sobre bases cuantitativas, un peso diferente de la figuración dentro de cada universo: los diseños figurativos predominan sobre los geométricos puros en Aguada, una situación que se invierte en Belén. Sin embargo, al recortar el conjunto figurativo, vemos que en ambos casos el repertorio iconográfico consta casi exclusivamente de referentes humanos y animales o sus índices y que, los atributos de composición seleccionados son semejantes, aspecto que en alguna medida podría estar condicionado por las características físicas y la forma de aprehensión visual del referente.

Por último, el ejericio nos obligó a reflexionar sobre la ausencia o escasez de referentes socioeconómicamente significativos en las representaciones visuales cerámicas de 
ambos momentos. El animal más significativo en términos económicos (camélido) está tan poco representado en la cerámica que no aparece en las muestras analizadas. Tampoco se representan objetos ligados a las actividades rutinarias. En Aguada no existe correspondencia directa entre la fauna consumida - en un sentido amplio- y la fauna representada. No son los animales que se cazan, crían, comen y/o usan los que se recrean en el mundo de la plástica. No hay allí correlación entre lo consumido o usado y lo representado; el arte mueble no alude al orden doméstico o cotidiano en el que está inmerso (Gordillo 2009). En la cerámica Belén, sin embargo, lo cotidiano tiene una presencia significativa ya que se registra buen número de representaciones de vizcachas y quirquinchos, dos animales que se consumían en forma recurrente (Belotti 2015, Miyano 2017).

En contraste, es importante señalar que, si bien no hemos incorporado en nuestro análisis las manifestaciones rupestres de Ancasti, sabemos que, en ellas, tal como sucede en el sitio de grabados del PDR, los camélidos tienen mayor protagonismo y son frecuentemente empleados como referentes. Aun así, como ocurre en la cerámica, la mayoría de las imágenes representadas parecen no recrear elementos de la vida diaria, sino más bien del mundo ritual y/o mítico.

Para concluir, reiteramos que este es un primer ensayo sobre el tema y su final es abierto. Sin duda, quedan muchos puntos sobre los que indagar, reflexionar, discutir y reformular con la profundización de esta nueva línea de trabajo que nos proponemos continuar a futuro.

Agradecimientos Este trabajo fue realizado en el marco de los proyectos UвACYт 20020130100108ва01 (SECYT, UBA), РICt2014-0594, 2012-0596 у 2012-0196 (АNPCYт). Mara Basile agradece al CONICET, al IDECU, a Norma Ratto, a los integrantes del PAch-A y a todos los que colaboraron en los relevamientos de las colecciones de materiales cerámicos y de los grabados rupestres aquí analizados. Inés Gordillo agradece a quienes le facilitaron el acceso a las colecciones mencionadas en este trabajo y a todos los colegas y amigos que participaron en las excavaciones de La Rinconada. A los evaluadores anónimos de este trabajo por sus aportes y bellos comentarios.

\section{NOTAS}

${ }^{1} \mathrm{Si}$ bien estas categorías resultan operativas para nuestro análisis, somos conscientes que los límites precisos entre la figuración y la no-figuración resultan con frecuencia arbitrarios y es difícil establecer si existe una diferencia de esencia o de grado entre ambas categorías, un problema que también se plantea con el arte occidental, de donde proviene en definitiva esta clasificación (Gordillo 2014a). Es probable que muchos motivos no-figurativos tengan un origen o correlato figurativo; al respecto es oportuno considerar el proceso de la reducción geométrica, fenómeno que conduce a las figuras explícitas de niveles figurativos variados hacia la reducción en figuras abstractas (Leroi-Gourham 1989). Asimismo, en el contexto social de su producción, los motivos no-figurativos pudieron representar o asociarse a referentes reales que desconocemos debido a la distancia semántica y temporal que nos separan de aquel (Groupe $\mu 1993$, Aschero 1975).

${ }^{2}$ Es el caso, por ejemplo, del "enmascarado" de Aguada, motivo por demás frecuente en ese estilo que representa a un personaje disfrazado de felino (H-F), el que seguramente tuvo una existencia real en las prácticas rituales de esas sociedades.

${ }^{3}$ Algunos de los motivos geométricos identificados en la muestra pueden tener un origen o correlato figurativo; por ejemplo, las series de escalonado-gancho son formalmente comparables a las series ofídico-felínicas y los escalonados radiales a las fauces del felino.

${ }^{4}$ El procedimiento más extendido es el grabado, pero frecuentemente es difícil distinguirlo claramente de la incisión debido a que suele ser realizado en estados intermedios del secado de la pasta, muchas veces incluso dentro de la misma pieza. Por ello, hablamos de grabado-inciso como un conjunto que alude a las técnicas de modificación de las superficies alfareras con un instrumento de punta antes de la cocción (Gordillo 2009).

${ }^{5}$ Estas asociaciones tienen significación estadística $\left(\mathrm{X}^{2} 132,441 / \mathrm{gl} / \mathrm{p}<0.001\right)$.

${ }^{6}$ Se ha corroborado recientemente el uso culinario y no funerario de "urnas" Santamariana y Belén, adscritas al PDR y procedentes del valle de Yocavil y de Fiambalá respectivamente, a través del análisis de los residuos culinarios contenidos en ellas (Lantos et al. 2017). 


\section{REFERENCIAS}

Aschero, C. 1975. Motivos y objetos decorados del sitio precerámico Inca Cueva 7 (Provincia de Jujuy). Antiquitas 20-21: 2-7.

AsSANDRI, S. 1991. Primeros resultados de la excavación en el sitio Martínez 1 (Catamarca, Argentina). Arqueología 46: 53-86.

Ávila, A. \& Herrero, R. 1991. Secuencia estratigráfica del sitio arqueológico Martínez 3, Dpto. Ambato, Catamarca. En Arqueología del Ambato, pp. 17-52. Córdoba: Publicaciones del CIFFYH.

BASILE, M. 2012. Imágenes en negro sobre rojo. Apuntes para delinear el estilo cerámico Belén (ca. 1100-1535 AD, Catamarca, Argentina). Alemania: EAE, LAP Lambert Academic Publishing GmbH \& Co.

BASILE, M. 2013a. Las manifestaciones plásticas de la región de Fiambalá: cambios y continuidades entre los siglos $\mathrm{v}$ al xv. En Delineando prácticas de la gente del pasado: Los procesos socio-históricos del oeste catamarqueño, N. Ratto, Comp., pp. 177-250. Buenos Aires: Serie Publicaciones sAA.

BASILE, M. 2013b. Imágenes en cerámica de la región de Fiambalá (Catamarca, Argentina). Cambios y continuidades entre los siglos IV y Xv. Chungara 45 (4): 581-597.

BAsile, M. \& RatTo, N. 2011. Colores y surcos. Una propuesta metodológica para el análisis de las representaciones plásticas de la región de Fiambalá (Tinogasta, Catamarca, Argentina). Boletín del Museo Chileno de Arte Precolombino 16 (2): 75-88.

BAsile, M. \& RATto, N. 2014. Images and memory: the case of the field of engravings of Guanchincito (ca. 1250-1400 AD, Catamarca, Argentina). En Theory, rock art and heritage. Proceedings of the XVI World Congress International Union of Prehistoric and Protohistoric Sciences (UISPP), Volumen 11, pp. 31-37. Cambridge: BAR International Series 2659.

Basile, M. \& Ratto, N. 2016. El aporte de las colecciones privadas al estudio de la arqueología regional: el caso de Saujil en la región de Fiambalá (Dpto. Tinogasta, Catamarca). Relaciones 41 (2): 423-430.

Bedano, M. C., Juez, S., \& Roca, S. 1993. Análisis del material arqueológico de la colección Rosso procedente del Departamento de Ambato, Provincia de Catamarca. Publicaciones 7.

Belotti, C. 2015. Desigualdad e intensificación de la subsistencia en el Valle de Yocavil (Catamarca y Tucumán, Argentina) entre los siglos I AC y XVI DC. Relaciones 40 (1): 73-100.

Bregante, O. 1926. Ensayo de clasificación de la cerámica del Noroeste Argentino. Buenos Aires: Ángel Estrada y Cía.

Criado Boado, F. 1999. Del terreno al espacio: planteamientos y perspectivas para la arqueología del paisaje. Capa. Criterios y convenciones en arqueología del paisaje 6: 1-55.

Cruz, P. 2004. Archéologie de la mort dans la Vallée d'Ambato. Homme et milieu dans le bassin de Los Puestos (CatamarcaArgentine) durant la Période d'Intégration Régionale
( $\mathrm{IV}^{\mathrm{e}}-\mathrm{X}^{\mathrm{e}}$ siècles après J.-C.). Tesis doctoral, Universidad de París I Pantheon Sorbonne, París. <https://www. researchgate.net/publication/279173883_Archeologie_de_la_mort_dans_la_Vallee_d\%27Ambato_Homme_et_milieu_dans_le_Bassin_de_Los_Puestos_CatamarcaArgentine_durant_la_Periode_d\%27Integration_Regionale_IVe-Xe_siecles_apres_J-C> [consultado 08-06-2019].

Gallardo, F. 2009. Sobre la composición y la disposición en el arte rupestre de Chile: consideraciones metodológicas e interpretativas. Magallania 37 (1): 19-38.

González, A. R. 1974. Arte, estructura y arqueología. Análisis de figuras duales y anatrópicas del Noroeste Argentino. Buenos Aires: Nueva Visión.

GonzÁlez, A. R. 1998. Cultura de La Aguada; arqueología y diseño. Buenos Aires: Filmediciones Valero.

Gordillo, I. 1998. Del barro a la figura. Caracterización de la alfarería Aguada de Ambato. En Homenaje a A. R. González, 50 años de aportes al desarrollo y consolidación de la Antropología Argentina, pp. 285-308. Buenos Aires: FFyL, UBA.

GordiLLO, I. 2001. Entre objetos, rocas y cuevas: significados y relaciones entre la iconografía rupestre y mobiliar de Aguada. En Arte en las rocas. Arte rupestre, menhires y piedras de colores, M. Podestá \& M. de Hoyos, Eds., pp. 101-111. Buenos Aires: Serie Publicaciones sAA.

Gordillo, I. 2004. El sitio ceremonial de La Rinconada. Organización socioespacial y religión en Ambato, Catamarca. Tesis de doctorado, FFyL, UBA.

Gordillo, I. 2009. Dominios y recursos de la imagen. Iconografía cerámica del valle de Ambato (Catamarca, Argentina). Estudios Atacameños 37: 99-121.

Gordillo, I. 2014a. "Motif" in the archeology of art. En Encyclopedia of global archaeology, C. Smith, Ed., pp. 50515052. Londres-Heildelberg: Springer New York-Dordrecht.

Gordillo, I. 2014b Ms. El sentido de lo ambiguo. Imágenes compuestas y alternancia perceptiva en la gráfica Aguada del Noroeste Argentino. Ponencia presentada al conAR I, p. 41, Rosario.

Gordillo, I. 2015. Las huellas del felino en la iconografía prehispánica del Noroeste argentino. ARKEOS 37: 2183-2190.

Gordillo, I. \& Solari, A. 2009. Prácticas mortuorias entre las poblaciones Aguada del valle de Ambato (Catamarca, Argentina). Revista española de Antropología Americana 39 (1): 31-51.

Gordillo, I. \& Vindrola-Padrós, B. 2017. Destruction and abandonment practices in La Rinconada, Ambato (Catamarca, Argentina). Antiquity 91 (355): 155-72.

Groupe $\mu 1993$. Tratado del signo visual. Para una retórica de la imagen. Madrid: Cátedra.

Juez, S. 1991. Unidad arqueológica Rodeo Grande, valle de Ambato: Excavación en el sitio Martínez 2. Publicaciones 46: 87-109.

KusCH, M. F. 1991. Forma, diseño y figuración en la cerámica pintada y grabada de la Aguada. En El arte rupestre en la 
arqueología contemporánea, M. Podestá, M. I. Hernández Llosas \& S. Renard de Coquet, Eds., pp. 14-24. Buenos Aires: Serie Publicaciones SAA.

Lantos, I., Palamarczuk, V., Orgaz, M., Ratto, N. \& Maier, M. 2017. Exploring the culinary uses of Santa María and Belén painted vessels from the Late Intermediate Period in Catamarca, Argentina. Journal of Archaeological Science Reports 18: 660-667.

Leroi-Gourhan, A. 1989. La prehistoria. Madrid: Labor.

Levi Strauss, C. 1967. Structural anthropology. Nueva York: Doubledary.

Miyano, J. P. 2017. El uso de animales por las sociedades agropastoriles tempranas: análisis zooarqueológico de un basural de la aldea de palo blanco (valle de Fiambalá, Catamarca). Arqueología 24 (1): 77-101.

Marconetto, M. B. 2015. El jaguar en flor. Representaciones de plantas en la iconografía Aguada del Noroeste Argentino. Boletín del Museo Chileno de Arte Precolombino 20 (1): 29-37.

Nazar, D., De la Fuente, G. \& Gheco, L. 2014. Entre cebiles, cuevas y pinturas. Una mirada a la estética antropomorfa del arte rupestre de La Tunita Catamarca, Argentina. Boletín del Museo Chileno de Arte Precolombino 19 (1): 35-49.

Orgaz, M. \& Ratto, N. 2012. Memoria y apropiación en paisajes agrícolas. En La espacialidad en arqueología: enfoques, métodos y aplicaciones, I. Gordillo \& J. M. Vaquer, Eds., pp. 191-226. Quito: Abya-Yala.
PeIRCE, C. 1894. ¿Qué es un signo? Navarra: Universidad de Navarra. <http://www.unav.es/gep/Signo.html > [consultado 08-06-2019].

Ratto, N. 1996 Ms. Relevamiento arqueológico del campo de petroglifos de Guanchincito (Fiambalá, Tinogasta, Catamarca), Informe presentado a la Municipalidad de Fiambalá, Catamarca.

Ratto, N. \& Basile, M. 2013. Funebria y animales (ca. 1250$1550 \mathrm{AD}$ ): una primera aproximación para el oeste tinogasteño, Catamarca, Argentina. En Delineando prácticas de la gente del pasado: los procesos socio-históricos del oeste catamarqueño, N. Ratto, Comp., pp. 251-278. Buenos Aires: Serie Publicaciones SAA.

Ratto, N., Orgaz M. \& Caletti S. 2000. Relevamiento arqueológico del campo de grabados de Guanchincito (Fiambalá, Dpto. Tinogasta, Catamarca). Cuadernos 19: 551-572.

Ratto, N., Orgaz, M., Basile, M., Feely, A., Coll, L., MiYANO, J. \& Mozo J. 2016. Las comunidades y su historia: patrimonio, museos y colecciones privadas. En La historia a través de las cosas, N. Ratto, Comp., pp. 91-98. Buenos Aires: Serie de Divulgación Científica de la Sociedad Argentina de Antropología.

WYNDVELDT, F. 2007. La estructura de diseño decorativo en la cerámica Belén (Noroeste Argentino). Boletín del Museo Chileno de Arte Precolombino 12: 49-67. 